\title{
¿Y si no ejercen su derecho de adquisición preferente, podemos vender? La importancia de reglas claras para el ejercicio de este derecho
}

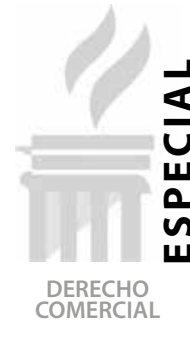

\author{
Diego Carrión Álvarez-Calderón \\ Abogado por la Pontificia Universidad Católica del Perú. \\ Máster en Derecho (LL.M.) por Harvard Law School. \\ Profesor de los cursos de Instituciones del Derecho Mercantil, Introducción a la \\ Metodología de la Investigación Jurídica y Derecho Mercantil I en la Pontificia \\ Universidad Católica del Perú.
}

SUMARIO:

I. Introducción.

II. El Derecho de Adquisición Preferente.

1. Razones e implicancias de Carácter Societario.

2. Razones e implicancias de Carácter Económico.

III. EI DAP en la Ley General de Sociedades Peruana.

1. EI DAP en la Sociedad Anónima Regular.

2. El DAP en la Sociedad Anónima Cerrada.

IV. Perspectiva civil del DAP.

1. La comunicación que realiza el Accionista Vendedor es una oferta.

2. El ejercicio del DAP por parte de los Accionistas Titulares se configura como la aceptación de la oferta.

3. Perfeccionamiento del contrato de compraventa de acciones como resultado de la aceptación por parte de los Accionistas Titulares de la oferta del Accionista Vendedor.

V. Situaciones problemáticas en torno al proceso de ejercicio del DAP.

1. ¿Qué significa ejercer el DAP?

2. ¿Cuál debe ser el plazo para ejercer el DAP?

3. ¿Cómo entender la previsión de que los Accionistas Titulares ejercerán su DAP “a prorrata" de su participación en el capital de la sociedad?

4. ¿Qué sucede con la aplicación del DAP ante la presencia de más de un Accionista Vendedor?

5. ¿Cómo debe ser establecido "el precio" en la comunicación que envíe el Accionista Vendedor?

6. ¿Cómo entender el deber de incluir el nombre del posible comprador en la comunicación que envíe el Accionista Vendedor?

7. ¿Cómo verificar que, en caso de no ejercicio del DAP, el Accionista Vendedor transfiera las acciones en las mismas condiciones informadas a los Accionistas Titulares?

VI. Conclusiones y reflexiones finales.

El autor desea expresar su agradecimiento a Miguel Ángel Pérez Carajulca, por su valiosa colaboración en la realización del presente artículo, que sin su participación no hubiera sido posible. 


\title{
RESUMEN:
}

Este artículo hablará sobre el derecho de adquisición preferente, las razones de su existencia y regulación, la forma como está regulado en nuestro sistema jurídico, la perspectiva civil del ejercicio de este derecho, para finalmente aterrizar en la problemática que podríamos enfrentar en una situación real. El autor propondrá una serie de recomendaciones para muchos de los problemas delineados, aunque no tienen una solución fácil y se deberá ver, caso por caso, la mejor manera de reducir o eliminar la aparición de esos problemas.

Palabras clave: Derecho de Adquisición Preferente, Accionista, Tercero, Capital Social, Acciones.

\begin{abstract}
:
The following article addresses the topic of Right of First Refusal, the reasons for its existence and regulation, also it will analyze the regulations adopted in the Peruvian legal system, the civil perspective of the exercise of this right, finally concluding with the challenges faced in reality. The author will propose recommendations onto many of the outlined issues, albeit there not being a simple solution and, each challenge should be analyzed on a case-by-case basis as the best way to reduce or eliminate said problems.
\end{abstract}

Keywords: Right of First Refusal, Shareholder, Third Party, Share Capital, Shares.

\section{INTRODUCCIÓN}

Con esa pregunta se cerró una reunión con un grupo de accionistas que estaba esperando concretar una venta de un bloque mayoritario de acciones, valuado en algunas decenas de millones de Dólares. El tercero interesado en la compra de las acciones había invertido centenas de miles de Dólares haciendo auditorías y due diligence, ambas partes habían invertido muchos meses negociando el precio de las acciones en venta, a determinación del beneficio bruto de explotación calculado antes de la deducibilidad de los gastos financieros - por sus siglas en inglés, "EBITDA" - especialmente. Se trataba de una venta asegurada a un competidor mundial de primer nivel, pero a pocas semanas del cierre aún quedaba esta pregunta en la cabeza de los accionistas vendedores, y si el bloque minoritario de accionistas no ejerce su derecho de adquisición preferente, ¿pode- mos vender igual nuestro bloque mayoritario? Si transcurre el plazo legal sin que el bloque minoritario se pronuncie sobre la carta oferta que les ha hecho llegar el gerente general de la sociedad target, ¿podemos vender al tercero sin problemas?

En la actualidad se pueden leer titulares como "Fusiones y Adquisiciones en Perú llegó a los US\$ 3,830 millones en el primer trimestre del año"1, lo cual podría significar una recuperación de esta actividad en nuestro país y, esperemos, podríamos estar iniciando una nueva ola de Fusiones y Adquisiciones para los siguientes cinco o diez años, similar a la vivida entre el 2004 y $2013^{2}$.

Bajo esa premisa, es importante que los accionistas de sociedades que tienen pensado participar en estas operaciones, revisen con cuidado muchas variables, entre económicas, financieras, contables, regulatorias, y muchas

1. Disponible en:<https://gestion.pe/economia/empresas/peru-registro-operaciones-us-3-830-millones-primertrimestre-ano-231350>.

2. "El Perú ha sido una de las economías de más rápido crecimiento en América Latina durante muchos años, con una tasa de crecimiento promedio de PBI de 6\% entre los años 2004 y 2013. Durante la desaceleración económica de la región, el PBI del Perú se mantuvo por encima del promedio, en 3.9\%. En este periodo, el mercado de M\&AMergers and Acquisitions - se dinamizó a tal punto, que se llegaron a registrar cifras de US\$10.000 millones, a partir de deals históricos, como la compra de una importante empresa cementera en Chile por parte del Grupo Breca, en 2009". REBAZA, Alberto. Disponible en: <https://elcomercio.pe/especial/zona-ejecutiva/tendencias/como-estamercado-fusiones-y-adquisiciones-noticia-1993093>. 
veces relegado a un plano inferior, legales. En nuestra experiencia, hemos llegado a momentos donde todas las variables - menos las legales- se habían tomado en cuenta para decidir proceder con una operación de compraventa de acciones, y al momento de revisar los aspectos legales encontrábamos situaciones que podrían poner en aprietos la transacción.

Entre esos aspectos legales que se deben tener en cuenta desde un inicio, especialmente, si existen más de un grupo de accionistas en la sociedad, es la regulación que existe en los documentos sociales del ejercicio del derecho de adquisición preferente. Por más que pueda parecer inofensivo, que se pueda pensar que llegado el momento ese punto "se verá" y "se superará", la realidad es que, llegado el momento sin haber tomado las precauciones del caso, podríamos llegar a un camino sin salida, y hasta a una transacción frustrada.

En este artículo hablaremos sobre el derecho de adquisición preferente, las razones de su existencia y regulación, la forma como está regulado en nuestro sistema jurídico, la perspectiva civil del ejercicio de este derecho, para finalmente aterrizar en la problemática que podríamos enfrentar en una situación real. Intentaremos, asimismo, proyectar recomendaciones a muchos de los problemas delineados, siendo que algunos - o muchos de ellos- no tienen una solución fácil y se deberá ver, caso por caso, la mejor manera de reducir - o eliminar - la aparición de esos problemas. Una asesoría legal diligente debe prever esta situación y advertir oportunamente a los clientes sobre los riesgos implícitos de no prestar atención a la existencia o a la correcta regulación de este derecho.

\section{EL DERECHO DE ADQUISICION PREFERENTE}

Es usual señalar que lo fundamental en una sociedad anónima es la reunión o concentra- ción de capitales para hacer negocios, sin ser de transcendental relevancia la calidad de las personas que la conforman. Se suele indicar así que, lo más característico de una sociedad anónima es su carácter "intuitu pecuniae", es decir, su atención al dinero aportado y no tanto así a quien lo aportó. Sin embargo, tales afirmaciones distan mucho de la realidad. En la práctica, en las sociedades anónimas los accionistas que las conforman suelen ser tan o más importantes que los capitales reunidos.

En la práctica comercial actual se observa que existen gran cantidad de sociedades anónimas constituidas por personas con estrechos lazos personales entre sí, derivados de su pertenencia al mismo grupo familiar, amical y/o empresarial. En estos casos, como indica Fernando De Trazegnies, "(...) la affectio societatis o intención de las partes de formar una sociedad y trabajar juntos dentro de ella, tiene un elemento personal basado en el conocimiento y la confianza recíprocos"3.

En estas sociedades la calidad de accionista de las personas inmersas en la sociedad se convierte en un valor fundamental que resguardar. Es en tal contexto, principalmente, que la figura del derecho de adquisición preferente -en adelante, "DAP" - juega un rol esencial en el mantenimiento de los accionistas originarios de una sociedad anónima. No obstante, como veremos más adelante, el papel del DAP dentro de una sociedad anónima no se agota en el cumplimiento de esta función.

El DAP es la prerrogativa que se les otorga a los accionistas de una sociedad para que, ante la potencial transferencia de acciones por parte de otro accionista, cuenten con la preferencia en la adquisición de tales acciones, usualmente, en los mismos términos en las que se las pretende transferir.

Esta prerrogativa puede ser legal o convencional. Es legal cuando proviene de la ley, como

3. DE TRAZEGNIES GRANDA, Fernando. "El Derecho de Adquisición Preferente en la Sociedad Anónima: La transferencia del control social a través de una sociedad holding". En: ADVOCATUS № 4. Lima: 2001, p. 231. 
por ejemplo la establecida en la Ley General de Sociedades -en adelante, "LGS" - peruana en su artículo 237 para las sociedades anónimas cerradas. Es convencional cuando está contemplada ya sea en el pacto social, en el estatuto o en un convenio de accionistas ${ }^{4}$.

El DAP se constituye como una excepción a la libre transmisibilidad de las acciones en una sociedad anónima. Por ello, es oportuno preguntarnos cuáles son las razones que justifican la existencia de un DAP.

Al respecto, en la doctrina tradicional se han utilizado razones de índole societario y legal, primordialmente, para explicar y justificar la regulación de un DAP ya sea en su variante legal o convencional; sin embargo, se ha dejado de lado las razones e implicancias económicas que existen detrás. A continuación, procederemos a analizar ambas razones tanto desde el punto de vista jurídico como económico, para luego poner de manifiesto la transcendencia del DAP en el marco de una transacción.

\section{Razones e implicancias de carácter societario.}

La principal razón para el establecimiento de un DAP en una sociedad anónima, desde el punto de vista societario, es evitar el ingreso de terceros extraños al accionariado de la sociedad. Los accionistas originarios emprenden un negocio teniendo como base su íntima relación personal, ya sea porque son familiares, íntimos amigos, miembros de un mismo gru- po social o empresarial, etc., y por lo mismo desean que el accionariado se mantenga en el tiempo sin que terceros ajenos se inmiscuyan en los asuntos de la sociedad. Ante ello, el DAP se presenta como un mecanismo idóneo para cumplir tal finalidad ${ }^{5}$.

A través del DAP los accionistas se aseguran de tener la preferencia en la adquisición de las acciones de la sociedad ante el interés de otro accionista de transferirlas a un tercero extraño a la sociedad. De esa manera, los accionistas titulares del DAP tendrán el poder de optar por el mantenimiento de la estructura societaria, a través de la adquisición de dichas acciones, o, contrariamente, por permitir que un tercero ingrese a la sociedad.

A esta razón se le debe agregar una razón adicional y complementaria desde el punto de vista societario, y es que el DAP además de velar por el mantenimiento de los accionistas originarios de la sociedad, también cuida de que estos mantengan inalterada su participación en el capital social, ya que en caso opten por adquirir las acciones, ello se realizará de manera proporcional a la participación de cada accionista en el capital de la sociedad.

Al respecto, decimos que es una razón adicional dado que el DAP se suele activar no solo ante la potencial transferencia de las acciones a un tercero, sino también hacia otro accionista de la sociedad", con lo cual el DAP además "(...) puede ser de utilidad cuando se quiera evitar que algún socio alcance una situación dominante $o$

4. El segundo párrafo del artículo 101 de la LGS habilita este tipo de pactos, al establecer que "Las limitaciones a la libre transmisibilidad de las acciones son de observancia obligatoria para la sociedad cuando estén contempladas en el pacto social, en el estatuto o se originen en convenios entre accionistas o entre accionistas y terceros, que hayan sido notificados a la sociedad (...)".

5. Al respecto, Fernando de Trazegnies indica que: "Este derecho tiene, entonces, por objeto dar una seguridad relativa a los accionistas de que, de buenas a primeras, no se van a encontrar como socios de una sociedad diferente, con otros accionistas, con una composición accionaria distinta, lo que puede dar lugar a que se decida su cambio de objeto social u otras modificaciones en aspectos substanciales de la organización o de la operación de la empresa, de modo que un grupo de accionistas se encuentre que forma parte de una sociedad que no es aquella en la que aportó su dinero y en la que no tiene ningún control ni confianza". En: DE TRAZEGNIES GRANDA, Fernando. Op. Cit., p. 232.

6. "Una venta interna no afectaría la relación personal - como en el caso de la venta a terceros - pero, en cambio, introduce variaciones de poder dentro de la sociedad". DE TRAZEGNIES GRANDA, Fernando. "El Derecho de 
participación mayoritaria en el capital"7. También es complementaria en cuanto complementa a la razón principal mencionada, pero a diferencia de esta, no es exclusiva del DAP, dado que la misma finalidad también se pretende alcanzar, por ejemplo, con el derecho de suscripción preferente.

Por lo tanto, sobre este punto, coincidiendo con Mila Guillén, podemos afirmar que el DAP en una sociedad anónima no solo vela por la permanencia del vínculo personal de los socios, sino también por mantener inalterada la estructura de poder original de la sociedad ${ }^{8}$.

Las razones mencionadas por sí mismas parecerían suficientes para justificar la presencia de un DAP dentro de una sociedad, sin embargo, existen también razones de índole económico que pueden ser tan o más importantes que las razones societarias indicadas. A ellas nos avocaremos a continuación, dada su relevancia dentro una sociedad y sus implicancias jurídicas y económicas en el marco de una eventual transacción.

\section{Razones e implicancias de carácter económico.}

Dentro de los pocos estudios que se han realizado en nuestro país sobre el DAP, no hemos encontrado alguno que haga referencia a las razones e implicancias económicas que tiene un
DAP dentro de una sociedad. Un interesante estudio al respecto ha sido realizado por los autores argentinos Iván Di Chiazza y Pablo Van Thienen?', quienes ponen de manifiesto la ausencia de estudios que reluzcan los aspectos económicos de un derecho de preferencia como el DAP ${ }^{10}$.

Como bien se menciona, el DAP:

"(...) se caracteriza por gozar de una formidable complejidad económica y reducir sus efectos motivadores o inhibitorios, según el caso, a un mero obstáculo de ingreso de terceros a una sociedad - cual derecho de admisión-, implica obviar toda su riqueza

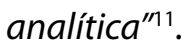

Esta complejidad económica se presenta en la práctica al momento de la activación del DAP en el marco de una transacción, es ahí cuando verdaderamente se pueden percibir los efectos del DAP y sus implicancias. Por lo cual, es necesario tener en consideración cuál es la complejidad económica del DAP y conocer sus consecuencias en la realidad para evitar complicaciones que podrían poner en "jaque" a una transacción.

Ahora bien, para una aproximación al carácter económico del DAP, es necesario, en primer lugar, poner de manifiesto que existen tres actores claves involucrados en el proceso de

Adquisición Preferente en la Sociedad Anónima: La transferencia del control social a través de una sociedad holding". En: ADVOCATUS N 4. Lima: 2001, p. 234.

7. RODRÍGUEZ PRIETO, Fernando. "La Sociedad Cerrada frente a los extraños". En: AAVV. Los Consejos del Notario. Madrid: El Inversor, 2000, p. 296.

8. GUILLÉN RISPA, Mila. En: INSTITUTO PERUANO DE DERECHO MERCANTIL (compilador). Tratado de Derecho Mercantil. Tomo I: Derecho Societario. Lima: Gaceta Jurídica, 2003, p. 910.

9. DI CHIAZZA, Iván y VAN THIENEN, Pablo. "El derecho de compra preferente como restricción a la transferencia de acciones. Análisis económico y jurídico". En: Revista DERECHO COMERCIAL Y DE LAS OBLIGACIONES N²006-B, año 39, 2006, pp. 705-730. Disponible en: <http://www.cedeflaw.org/pdfs/2017426172231-128.pdf>.

10. "En efecto, usualmente la negociación jurídica sobre las limitaciones a la transferencia de acciones y en particular sobre el RFR (Right of First Refusal, es una variante norteamericana del DAP), se reduce a consideraciones de mera técnica jurídica con relación al funcionamiento y ejercicio de la preferencia, más no se desarrolla previamente una apreciación económica sobre la conveniencia de esta especial restricción, en cuanto a si favorece al vendedor o al titular del derecho, a ambos, al tercero potencial comprador o a ninguno de los actores en danza y sobre todo, si en función de tal análisis existen alternativas o variantes para el RFR". lbíd., p. 11.

11. Ibíd., p. 709. 
ejercicio del DAP: (i) el accionista interesado en transferir sus acciones -en adelante, el "Accionista Vendedor"12"-, (ii) los accionistas titulares del DAP —en adelante, los "Accionistas Titulares" - y (iii) el tercero interesado en la adquisición —en adelante, el "Tercero Interesado" - . Para todos estos actores la limitación a la transferencia de acciones que significa el DAP tiene efectos económicos e implicancias prácticas importantes a considerar.

Así pues, se tiene que tener presente que el DAP involucra determinados costos económicos ${ }^{13}$ para los sujetos involucrados. Sería ingenuo y hasta negligente pretender que una restricción semejante sea gratuita e inocua, en términos de eficiencia económica, para los intervinientes, tal cual como lo ponen de manifiesto Di Chiazza y Van Thienen ${ }^{14}$. Por ello se debe tener en cuenta estos costos económicos tanto en la incorporación del DAP en una sociedad, como en el momento que es ejercido en el marco de una transacción. Veamos en qué consisten:

"Desde la perspectiva del análisis económico, toda relación entre agentes económicos que implique transferencia de dominio, como así mismo las negociaciones concernientes a cualquier restricción y limitación que condicionare aquella transferencia, involucra costes, valores y objetivos específicos de los agentes participantes del negocio"15.
En tal contexto, una eventual transferencia de dominio de las acciones de una sociedad no está exenta de estas consideraciones económicas básicas, más aún si hay un DAP de por medio. La existencia de un DAP en una sociedad pone en una situación transversalmente distinta a los accionistas y terceros interesados en adquirir, que en el caso de que no la hubiera, como veremos en adelante.

EI DAP lleva consigo una serie de incentivos y restricciones para los actores involucrados. Dentro del proceso del DAP cada uno tendrá a su vez intereses y objetivos distintos. El Accionista Vendedor buscará obtener el mayor valor posible por sus acciones, los Accionistas Titulares desearán mantener el accionariado de la sociedad inalterado sin incurrir en costos elevados por la compra de las acciones y el Tercero Interesado procurará la adquisición de las acciones por el menor precio posible y sin incurrir en costos adicionales como la dilación de tiempo por extensión del proceso de DAP o por eventuales conflictos con los Accionistas Titulares que puedan cuestionar su adquisición.

Dado que no todos los actores involucrados podrán satisfacer de igual manera sus intereses y conseguir sus objetivos, es relevante que se conozca la complejidad y operatividad del DAP, asimismo entender cómo este puede coadyu-

12. Utilizamos el término "Accionista Vendedor" para efectos prácticos, ya que en la mayoría de casos la transferencia de las acciones se realizará en el marco de una compraventa de acciones. Sin perjuicio de ello, reconocemos que dicha transferencia también puede ser realizada mediante otros mecanismos, tales como cesiones de derechos, donaciones, permutas, etc. y en general, mediante cualquier medio contractual de transferencia de la propiedad. En ese sentido, este término abarca también a estas figuras.

13. "La interpretación del concepto de costo económico se basa en la doctrina del "costo de oportunidad". Se trata del mejor rendimiento obtenido por un recurso en una actividad alternativa; los costos económicos, a diferencia de los contables que son explícitos, incluyen conceptos no registrados - es decir quedan implícitos- (...). A los costos económicos suele denominárselos "costes" para diferenciarlos de los contables". EUMED.NET - Enciclopedia Virtual.

Disponible en: <http://www.eumed.net/diccionario/definicion.php?dic=4\&def=651>. En el mismo sentido, COOTER, Robert y Thomas ULEN. Derecho y Economía. México: Fondo de Cultura Económica, 1999, p. 49.

14. DI CHIAZZA, Iván y VAN THIENEN, Pablo. Op. Cit. p. 709.

15. Ibíd., p. 710. Los autores citados entienden por "costes" $a$ : "(...) todo aquello que el agente económico está dispuesto a sacrificar - sea gastando de representará más o ganando de menos - en aras de conseguir determinado objetivo - un bien tangible o intangible - que, una vez obtenido, un valor - material o inmaterial - en un plazo mediato o inmediato y que el agente espera que compensará y superará el sacrificio — coste-inicial". 
var a la satisfacción de sus propósitos o, por el contrario, frustrarlos.

Para tales efectos, a continuación, desarrollaremos desde el punto de vista económico los objetivos, efectos y consecuencias que tiene el DAP ante una eventual transferencia de acciones.

\section{a) Objetivos y efectos económicos del DAP en una sociedad}

\section{i. Restricción del ingreso al accionariado de la sociedad de Terceros Interesados}

Ya hemos señalado que una de las razones fundamentales que justifica el establecimiento de un DAP en una sociedad anónima es el restringir el ingreso de terceros extraños a la sociedad. El sentido de esta restricción no se centra únicamente en mantener el carácter cerrado de la sociedad, sin más razón, sino que con ello se quiere evitar, de plano, las consecuencias negativas que se podrían derivan de la injerencia de terceras personas en los asuntos sociales.

A manera de ejemplo, determinadas sociedades buscarán con el DAP evitar que ciertas personas entren a su negocio, tales como competidores comerciales, sujetos de dudosa reputación, inversionistas que modifiquen el rumbo de la sociedad, etc.; o, en general, evitar perder el control de su sociedad. El margen de lo posibilidades de afectación es muy grande y los riesgos diversos.

Sin perjuicio de lo mencionado, es importante resaltar que el ingreso de terceros a una sociedad no necesariamente acarrea consecuencias negativas para la sociedad. En muchos casos, tal ingreso se podría considerar incluso necesario y beneficioso. No obstante, el costo de oportunidad que los Accionistas Titulares asumen al adquirir las acciones del Accionista Vendedor precisamente, está constituido por los beneficios que el Tercero Interesado podría aportar a la sociedad. Claro está, de acuerdo con el análisis costo-beneficio que realicen los Accionistas Titulares, bien podrían optar por no ejercer su DAP y permitir el ingreso del Tercero Interesado.

Ahora bien, como mencionan Di Chiazza y Van Thienen ${ }^{16}$, estas funciones constituyen tan solo uno de los aspectos económicos del DAP, el mismo presenta una lógica económica más compleja; el DAP, además, conlleva un doble efecto "desmotivador" $y$ "motivador" para el Accionista Vendedor, según el contexto en el que se esté.

Veamos en qué consisten.

\section{ii. Los efectos "motivador" $y$ "desmotivador" del DAP}

Como se ha mencionado, la inclusión del DAP en una sociedad tiene una serie de consecuencias aparejadas. Una de ellas viene dada por el efecto de, según las circunstancias, motivar o desmotivador la venta de las acciones por parte del Accionista Vendedor. Al respecto, es importante, en primer lugar, identificar si el Accionista Vendedor desea transferir la totalidad de sus acciones en la sociedad o sólo una parte de ellas. Según sea el caso, el DAP tendrá efectos distintos en él.

De encontrarnos ante una transferencia parcial de las acciones del Accionista Vendedor, Di Chiazza y Van Thienen ${ }^{17}$ indican que, el objetivo que cumple el DAP consistiría en "desmotivar" la venta de sus acciones, toda vez que existirá un interés particular de su parte por evitar o restringir el incremento de control accionario de los Accionistas Titulares.

Así las cosas:

"(...) si puesto el vendedor en trance de tener que escoger entre vender sus acciones, disparando el RFR - con la posibilidad real de que el titular del mismo ejerza su derecho de compra

\footnotetext{
16. Ibíd., p. 711.

17. Ibíd. p. 712.
} 
preferente-yel objetivo - empresario, estratégico, personal o cual fuere - de evitar que el titular del RFR alcance mayores umbrales de control o poder corporativo, es obvio que deberájustipreciar el mayor beneficio o el menor coste entre una y otra alternativa"18.

Nótese que, en este escenario, la sola presencia del DAP no significa que el Accionista Vendedor se limitará a no vender sus acciones, sino que implicará un mayor análisis de costo-beneficio por su parte, de manera previa a la activación del DAP. En ese sentido:

"(...) si el vendedor de las acciones valorara como primordial evitar el potencial incremento accionario del titular del RFR, ergo, el vendedor no le debería brindar al titular del RFR la chance de comprar sus acciones, con lo cual en definitiva, las acciones podrían no ser vendidas"19.

Por otro lado, distinto se presenta el caso si es que el Accionista Vendedor desea transferir la totalidad de su accionariado en la sociedad, en este supuesto el DAP cumpliría un efecto "motivador" para la salida de este accionista ${ }^{20}$, esencialmente porque tendrá, mínimamente, dos potenciales compradores - los Accionistas Titulares y el Tercero Interesado-.

Con la presencia del DAP en el marco de una transacción, el Accionista Vendedor se colocaría en una posición más ventajosa de la que estaría en ausencia del DAP ya que, al multiplicarse el espectro de potenciales compradores, lo natural sería el surgimiento de un ambiente competitivo entre los Accionistas Titulares y el Tercero Interesado. Competencia que, sin duda, favorecería al Accionista Vendedor al permitirle incrementar sus posibilidades de recibir un mejor valor por sus acciones.

Es oportuno resaltar que hablamos de "valor"y no de "precio" por las acciones, porque no nece- sariamente, en el contexto de una transacción, el ofrecimiento de un precio más elevado otorga per se mayor valor a las acciones, ni tampoco coloca automáticamente al Accionista Vendedor en una mejor posición que determine la transferencia de sus acciones a uno $\mathrm{u}$ otro interesado.

Al contrario, serán probablemente otros los factores los que inclinen la balanza para la concretización de la transferencia, tales como el pago de la totalidad del precio por las acciones al contado y no a plazos; la eliminación de cuentas de garantía que retengan parte del monto a pagar por las acciones; reducción o eliminación de obligaciones y garantías a cargo del Accionista Vendedor; supresión de supuestos de indemnización a favor del comprador; etc. Estas modificaciones pueden poner en una mejor posición al Accionista Vendedor de la que hubiera estado por tan solo recibir un mayor precio.

Como se puede notar entonces en este escenario, el DAP, además de motivar la salida del Accionista Vendedor, sirve como un mecanismo de asignación de mayor valor a las acciones objeto de la transferencia, favoreciendo así al Accionista Vendedor.

Sin perjuicio de lo anterior, debemos reconocer que no siempre el DAP favorecerá al Accionista Vendedor. En determinados supuestos, la activación del DAP podría significar la frustración de la transferencia de las acciones, como ya veremos y analizaremos más adelante a detalle.

Recopilando lo mencionado en este acápite, el DAP lleva consigo ciertos efectos económicos dignos de tener en consideración al momento de establecer un DAP en una sociedad y/o en el momento de su activación. De acuerdo con las circunstancias concretas de cada caso, el mismo puede significar el motivar o desmotivar al Accionista Vendedor de efectuar la transferencia o no de sus acciones. Asimismo, el DAP

18. Loc. Cit.
19. Loc. Cit.
20. Loc. Cit. 
potencialmente pondría en una mejor posición al Accionista Vendedor para recibir un mayor valor por sus acciones.

\section{b) Consecuencias económicas del DAP en los actores involucrados}

Hasta este punto hemos adelantado los objetivos y efectos que puede tener el DAP dentro de la sociedad, principalmente, respecto de los Accionistas Titulares y del Accionista Vendedor. Sin embargo, existe otro actor clave a quien también le alcanzan los efectos y objetivos del DAP: el Tercero Interesado, quien tendrá que afrontar consecuencias negativas o positivas, de ser el caso, producto de la operatividad del DAP.

Por ello, en adelante nos centraremos en las consecuencias económicas del DAP tanto en el Accionista Vendedor, en los Accionistas Titulares y en el Tercero Interesado. Veremos cómo la activación del DAP y las decisiones que cada uno de estos sujetos tome al respecto tendrán importantes efectos en los demás. Estos tres actores si bien no están conectados por relaciones jurídicas directas, si están vinculados económicamente, en cuanto al DAP se refiere.

\section{i. Posición del Accionista Vendedor}

En cuanto a la posición del Accionista Vendedor ya analizamos anteriormente que el DAP puede tener efectos motivadores o desmotivadores de acuerdo con el caso en concreto. Además, pusimos de manifiesto que el DAP otorga la posibilidad a este accionista de poder ver incrementado el valor de sus acciones producto del proceso competitivo que se crea entre en el Tercero Interesado y los Accionistas Vendedores. Mencionamos también que, sin perjuicio de lo dicho, no siempre el DAP tendrá consecuencias positivas en el Accionista Vendedor.

El esquema competitivo que se activa a consecuencia del DAP puede significar un arma de doble filo para el Accionista Vendedor ya que, si bien podría, mayormente, beneficiarlo; también cabe la alta posibilidad de que tenga consecuencias negativas en él. Nos explicamos: al existir al menos dos potenciales compradores, los Accionistas Titulares y el Tercero Vendedor, podría suceder que al final ninguno de los dos termine concretando la transacción y ello a causa de la operatividad del DAP mismo.

Un DAP con una regulación deficiente y/o mal planteado podría tener consecuencias negativas en la transacción, debido principalmente a la ausencia de reglas claras, lo cual a la postre podría significar una dilación innecesaria del plazo de operatividad del DAP; o, más grave aún, generar incertidumbre respecto a la realización de un proceso adecuado de ejercicio del DAP por parte de los Accionistas Titulares. Todo ello tendría como desenlace la pérdida de interés por parte del Tercero Interesado y, por ende, la caída de la transacción respecto a él.

Como consecuencia de la pérdida de interés del Tercero Interesado podría suceder que los Accionistas Titulares, al ya no ver amenazada su posición dentro de la sociedad por el ingreso de un extraño, decidan simplemente no ejercer su DAP y de esa manera no adquirir las acciones del Accionista Vendedor. La posible adquisición, en este caso, por parte de los Accionistas Titulares se frustra también.

Como se podrá notar, las consecuencias positivas para el Accionista Vendedor están supeditadas a una regulación adecuada del DAP en una sociedad y al correcto ejercicio del mismo al momento de su activación. Lo contrario puede convertir al DAP en un enemigo de la transacción toda vez que puede significar su frustración.

Más adelante, a la vez que analizamos a detalle las situaciones problemáticas que podrían ocasionarse por una insuficiente regulación y un inadecuado ejercicio del DAP, plantearemos algunos lineamientos para evitar el entorpecimiento y una posible caída de una transacción.

\section{ii. Posición de los Accionistas Titulares}

EI DAP tiene efectos significativos e interesantes en los Accionistas Titulares que es importante analizar. El efecto más notorio viene dado por el escudo protector que el DAP crea en estos ante el posible cambio de su posición en el acciona-

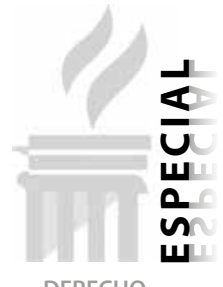


riado de la sociedad, ya sea por la entrada de un tercero o por el incremento de poder de otros accionistas. Sin embargo, no es el único efecto ni consecuencia que se crea en sus posiciones.

Como consecuencia del DAP, los Accionistas Titulares podrían ver reducidos significativamente sus costos transaccionales ${ }^{21}$ en la adquisición de las acciones ofertadas por el Accionista Vendedor, ello toda vez que una vez que se active el proceso del DAP recibirán una propuesta de transferencia de las acciones que, en el mejor de los casos, ha sido minuciosamente preparada por el Tercero Interesado o por el Accionista Vendedor. Con lo cual los costos de negociación de los Accionistas Titulares se verían reducidos.

De esa manera, con la presencia del DAP los Accionistas Titulares se encontrarían en una mejor posición de la que estarían en su ausencia. Sin embargo, debemos mencionar que se podrían generar también ciertas desventajas para estos con la activación del DAP.

Si bien, como dijimos, en el mejor de los casos los Accionistas Titulares pueden recibir una propuesta bien realizada para la adquisición de las acciones, también podría pasar que, en otros escenarios, reciban una propuesta que no refleje necesariamente el valor de las acciones en transferencia. En tal caso, dado que usualmente los plazos para el ejercicio de su DAP son cortos, el tiempo que tendrán para poder analizar la propuesta puede jugarles en contra y podrían terminar adquiriendo por un precio muy elevado o, peor aún, no concretizando la adquisición de las acciones por tal razón.

Adicionalmente, en el caso de los Accionistas Titulares existe un factor relevante a tomar en consideración en el marco del DAP, hablamos del "Idiosyncratic Value", referido a que suele existir una elevada valoración subjetiva e intangible ${ }^{22}$ por parte de los accionistas de una sociedad por las acciones de la misma. Ello se muestra entendible toda vez que son los accionistas quienes están más familiarizados con la sociedad, más aún si están involucrados en el día a día de la misma y/o si se trata de los accionistas originarios, la valoración en tal caso que realizan de las acciones no solo cuenta con parámetros objetivos sino principalmente subjetivos.

Lo dicho es importante ya que, ante el escenario de potencial transferencia de las acciones por parte del Accionista Vendedor a un Tercero Interesado, los Accionistas Titulares estarán más propensos a ejercer su DAP, y con ello, quedarse con las acciones de su sociedad. Incluso, estarían dispuestos a realizar una mejor oferta por las acciones al Accionista Vendedor, poniendo así a este en una posición más beneficiosa, tal como se explicó anteriormente, y sacando del juego al Tercero Interesado. Todo ello en virtud del Idiosyncratic Value.

Por lo dicho, los efectos y consecuencias que tiene el DAP en los Accionistas Titulares, así como el rol que puede desempeñar el Idiosyncratic Value, son cuestiones de ineludible análisis tanto para el Accionista Vendedor como para el Tercero Interesado, por los efectos colaterales que pueden tener en estos.

\section{iii. Posición del Tercero Interesado}

Se ha hablado ya del Accionista Vendedor, así como de los Accionistas Titulares y se han analizado los efectos y consecuencias económicas que el DAP puede causar en ellos. Es momento de hablar del último actor involucrado dentro del DAP: el Tercero Interesado.

En términos legales, la relación jurídica que se crea con la regulación y activación del DAP está compuesta únicamente por dos partes: el Accionista Vendedor y los Accionistas Titulares. Son ellos los que están vinculados jurídicamente y es sobre ellos que recaen los derechos, deberes y obligaciones que surgen a propósito del DAP.

21. Ibíd., p. 716.

22. Ibíd., p. 713. 
Sin embargo, el Tercero Interesado, si bien en estricto no cuenta con una relación jurídica con el Accionista Vendedor o con los Accionistas Titulares que se derive directamente del DAP, sí se encuentra vinculado con ellos económicamente.

Nos explicamos: ya sea de manera directa o indirecta, el Tercero Interesado es quien promueve la activación del DAP. De manera directa, cuando es él quien realiza la propuesta de adquisición de las acciones al Accionista Vendedor; o, indirectamente, cuando es este el destinatario de la propuesta de transferencia de acciones elaborada por el Accionista Vendedor. En ambos escenarios, el Accionista Vendedor tendrá que activar el DAP para poder concretizar la transferencia de las acciones.

En caso de ser el Tercero Interesado quien realice la propuesta de adquisición de las acciones, será su propuesta la que determinará los términos y condiciones de la eventual adquisición por parte de los Acciones Titulares. Lo cual significará que todo el contenido económico de la propuesta será asumido por los Accionistas Titulares, en caso estos decidan ejercer su DAP. Asumiendo con ello no solo las ventajas de la propuesta, sino también los posibles errores y riesgos inherentes de la misma.

De igual modo, el Tercero Interesado, de manera previa a la presentación de su propuesta de adquisición al Accionista Vendedor, tendrá que incurrir en una serie de costos para recolectar información y evaluar el valor de las acciones ${ }^{23}$ para tomar una decisión de si efectuar la propuesta de adquisición o no. Ello, con el riesgo de que, al final, la adquisición de las acciones por su parte no llegue a concretarse debido al ejercicio del DAP por los Accionistas Titulares, quienes tienen preferencia en la adquisición sobre él ${ }^{24}$.
Por lo dicho, los costos y riesgos que asume el Tercero Interesado no son menores. Más aún, si tenemos en cuenta que este tercero parte de una posición de desventaja respecto de los Accionistas Titulares, ya que ellos usualmente disponen de más y mejor información para valuar sus acciones a diferencia del Tercero Interesado, quien si bien podría conseguir la información adecuada y lograr una valuación real, lo cierto es que ello supone costos de los cuales los Accionistas Titulares podrían prescindir ${ }^{25}$. De esa manera, al estar en una mejor posición, los Accionistas Titulares podrían optar por ejercer su DAP en caso consideren que el precio ofrecido por el Tercero Interesado se ajusta al valor de las acciones.

Como corolario respecto a este punto, será de suma relevancia que el Tercero Interesado tenga en cuenta y prevea que, ante una transacción en la cual esté presente el DAP, será muy probable que los Accionistas Titulares, además de tener mayor información sobre la sociedad y por ende sobre el valor de las acciones, cuenten con una valoración subjetiva y personal de las acciones de la sociedad, de muy difícil medición ${ }^{26}$-el Idiosyncratic Value mencionado líneas anteriores-. Todo lo cual llevaría a un incremento de la posibilidad, y consecuente riesgo para el Tercero Interesado, de que los Accionistas Vendedores opten por ejercer su DAP y por ende adquieran las acciones objeto de la transacción. Esto, claro está, siempre en la medida que se cumplan algunas premisas básicas a efectos de que los Accionistas Titulares ejerzan su DAP: (a) que estos cuenten con los recursos suficientes para poder adquirir las acciones en venta, (b) que cuenten con el tiempo y las ganas de asumir un mayor riesgo en la operación del negocio - al asumir una mayor participación-, y (c) en caso de ser de edad avanzada, no tengan problemas sucesorios en los cargos gerenciales y/o directivos.

\footnotetext{
23. Ibíd., pp. 713 - 714.

24. Ibíd., p. 714.

25. Loc. Cit.

26. Loc. Cit.
} 
Teniendo en consideración lo mencionado en líneas anteriores, Di Chiazza y Van Thienen concluyen sobre este punto que no es difícil advertir que el DAP, desde la perspectiva económica, generaría inhibición de la compra de las acciones para el Tercero Interesado ${ }^{27}$. Por nuestra parte, consideramos que ello es parcialmente cierto, ya que, si bien en algunos casos los Terceros Interesados pueden verse inhibidos de participar en la adquisición de las acciones de una sociedad que cuente con un DAP, en la mayoría de situaciones, creemos que ello no será obstáculo para que participen del proceso de adquisición de tales acciones. Lo importante será contar con reglas claras para el ejercicio del DAP y llevar a cabo un proceso adecuado para su ejercicio.

\section{EL DAP EN LA LGS PERUANA}

Habiendo explicado las razones e implicancias tanto societarias como económicas del DAP en la sociedad y en los actores involucrados, es momento de analizar su regulación dentro de la LGS. Al respecto, en nuestro derecho societario contamos con ambas variantes del DAP, tanto el DAP de fuente legal como el DAP convencional para la sociedad anónima.

Sobre lo dicho, es necesario realizar las siguientes precisiones. Primero, el único tipo de sociedad anónima para el cual la LGS establece un
DAP lega ${ }^{28}$, es decir, regulado expresamente en este texto normativo, es la sociedad anónima cerrada —en adelante, "SAC" - . Segundo, en el caso de la sociedad anónima regular el DAP puede venir establecido ya sea en el pacto social, en el estatuto o en convenios de accionistas, esto es, estamos ante un DAP de tipo convencional. Finalmente, en la sociedad anónima abierta, por regla general, el DAP se encuentra prohibido por lo dispuesto en el artículo 254 de la LGS ${ }^{29}$.

\section{EI DAP en la sociedad anónima regular.}

La sociedad anónima regular si bien no tiene un DAP legal previsto específicamente para ese tipo societario, ello no es obstáculo para que los accionistas puedan regularlo ya sea en el pacto social, en el estatuto o mediante convenios de accionistas; toda vez que el artículo 101 de la LGS los habilita a hacerlo. En efecto, este artículo referido a las limitaciones a la transferencia de acciones, en su segundo párrafo, estipula lo siguiente:

"Las limitaciones a la libre transmisibilidad de las acciones son de observancia obligatoria para la sociedad cuando estén contempladas en el pacto social, en el estatuto o se originen en convenios entre accionistas o entre accionistas y terceros, que hayan sido notificados a la sociedad (...)".

27. Loc. Cit.

28. Hacemos notar que, como se habrá visto hasta este punto, nuestro artículo se concentra en el DAP aplicado a la sociedad anónima, por lo cual no es objeto de estudio en esta ocasión el DAP legal contemplado en el artículo 291 de la LGS para la sociedad comercial de responsabilidad limitada. Si bien no negamos que gran parte del análisis aquí desarrollado bien le podría ser de aplicación, ello ameritaría un estudio detallado de ese caso societario en específico, lo cual escapa al objeto de este escrito.

29. "Articulo 254.- Estipulaciones no válidas

No son válidas las estipulaciones del pacto social o del estatuto de la sociedad anónima abierta que contengan:

1. Limitaciones a la libre transmisibilidad de las acciones;

2. Cualquier forma de restricción a la negociación de las acciones; 0

3. Un derecho de preferencia a los accionistas o a la sociedad para adquirir acciones en caso de transferencia de éstas.

La sociedad anónima abierta no reconoce los pactos de los accionistas que contengan las limitaciones, restricciones o preferencias antes referidas, aun cuando se notifiquen e inscriban en la sociedad.

Lo previsto en este artículo no es de aplicación a las clases de acciones no inscritas de conformidad con lo previsto en el Artículo 252." 
Así, el DAP, al significar una limitación a la libre transmisibilidad de las acciones, se constituirá de observancia obligatoria para la sociedad y por ende para los accionistas cuando esté contemplado en alguno de los instrumentos indicados. Por ello, en el caso de este tipo de sociedades, cuando los accionistas deseen contar con la preferencia en la adquisición de acciones de su sociedad en el supuesto de que otro accionista pretenda transferir sus acciones, tendrán que preverlo expresamente en alguno de estos documentos societarios.

Cabe mencionar que, cuando el DAP sea regulado en el pacto social o en el estatuto de la sociedad, el mismo será aplicable para todos los accionistas, originarios y futuros, y será obligatorio per se frente a la sociedad. En cambio, si el DAP se encuentra establecido en un convenio de accionistas - entre accionistas o entre estos y terceros - para que este surta efectos frente a la sociedad, dicho convenio tendrá que serle notificado y solo será aplicable entre las partes de ese convenio en específico, mas no para los accionistas no participantes.

Ahora bien, en el caso de sociedades anónimas regulares no existe un modelo específico de regulación del DAP, por lo cual lo que se suele hacer en la práctica es adoptar y adecuar el modelo de DAP regulado en el artículo 237 de la LGS para la SAC. En ese sentido, será relevante el análisis que se realice del DAP regulado para este tipo societario, a lo cual nos avocaremos a continuación.

\section{EI DAP en la sociedad anónima cerrada.}

Dentro del ordenamiento societario peruano, en lo que respecta a sociedades anónimas, la SAC es la única que cuenta con un DAP regulado expresamente en la LGS. Las razones que justifican tal opción del legislador peruano son, esencialmente, razones de índole societario destinadas a mantener el carácter cerrado y el control de la SAC.

Dado que la SAC "(...) se trata de una modalidad en la que los accionistas tienen interés en mantener el desarrollo de una actividad económica bajo el control y en beneficio de un número reducido de personas $(. . .)^{1 / 30}$, el DAP, al otorgar preferencia a los accionistas ante una eventual venta de las acciones de la SAC, sirve como una herramienta para cumplir el interés de los accionistas de mantener el grupo accionario originario de su sociedad.

La SAC se configura, así como una sociedad en la cual el elemento personal prima sobre el factor capital. Fernando De Trazegnies indica al respecto que:

\section{“(...) en la sociedad anónima cerrada, donde los socios han decidido reunirse y constituir una empresa con el ánimo de mantenerla entre ellos, la affectio societatis intuitu per- sonae es más intensa y más particularizada: los socios tienen una confianza personal unos en los otros" 131 .}

Entonces, el DAP legal regulado en la LGS está destinado a mantener el valor personal que es tan característico de las SAC. En palabras de Enrique Elías, el DAP está establecido "(...) con el propósito de cautelar el interés de los accionistas de mantener la titularidad de las acciones en poder del pequeño grupo inicial (... . $)^{1 / 32}$. No obstante cumplir este propósito, se debe tener en cuenta que el DAP puede tener propósitos adicionales y así como importantes implicancias económicas a considerar, tal como ha sido explicado anteriormente.

\subsection{La regulación del DAP en el artículo 237 de la LGS.}

La regulación del DAP para la SAC está contenida en el artículo 237 de la LGS, que a su letra establece:

30. ELÍAS LAROSA, Enrique. "Derecho Societario Peruano. La Ley General de Sociedades". Tomo Il. Tercera Edición. Edición puesta al día por el Estudio Rodrigo, Elías \& Medrano. Lima: Gaceta Jurídica, 2015, p. 76.

31. DE TRAZEGNIES GRANDA, Fernando. Op. Cit., p. 232.

32. ELÍAS LAROSA, Enrique. Op. Cit., p. 83. 
"Artículo 237.- Derecho de adquisición preferente

El accionista que se proponga transferir totalo parcialmente sus acciones a otro accionista o a terceros debe comunicarlo a la sociedad mediante carta dirigida al gerente general, quien lo pondrá en conocimiento de los demás accionistas dentro de los diez días siguientes, para que dentro del plazo de treinta días puedan ejercer el derecho de adquisición preferente a prorrata de su participación en el capital.

En la comunicación del accionista deberá constar el nombre del posible comprador $y$, si es persona jurídica, el de sus principales socios o accionistas, el número y clase de las acciones que desea transferir, el precio y demás condiciones de la transferencia.

El precio de las acciones, la forma de pago y las demás condiciones de la operación, serán los que le fueron comunicados a la sociedad por el accionista interesado en transferir. En caso de que la transferencia de las acciones fuera a título oneroso distinto a la compraventa, o a título gratuito, el precio de adquisición será fijado por acuerdo entre las partes o por el mecanismo de valorización que establezca el estatuto. En su defecto, el importe a pagar lo fija el juez por el proceso sumarísimo.

El accionista podrá transferir a terceros no accionistas las acciones en las condiciones comunicadas a la sociedad cuando hayan transcurrido sesenta días de haber puesto en conocimiento de esta su propósito de transferir, sin que la sociedad y/o los demás accionistas hubieran comunicado su voluntad de compra.

El estatuto podrá establecer otros pactos, plazos y condiciones para la transmisión de las acciones y su valuación, inclusive suprimiendo el derecho de preferencia para la adquisición de acciones".
Lo primero que se debe mencionar sobre el artículo 237 de la LGS es que su aplicación es de carácter supletorio. Ello significa que, salvo pacto en contrario establecido en el estatuto de la SAC sobre la preferencia de los accionistas en el caso de transferencia de acciones, será de aplicación el DAP regulado en este artículo. Siendo incluso posible la supresión del DAP en una SAC, si así lo acuerdan los accionistas en el estatuto.

Así las cosas, este artículo establece el procedimiento que debe seguir todo aquel accionista que pretenda transferir sus acciones dentro de la SAC, ya sea total o parcialmente. El primer paso consiste en comunicar a la sociedad - a través de una carta dirigida al gerente general - la intención de transferencia de las acciones a un tercero o incluso a otro accionista. Esta carta debe contener las condiciones de la eventual transferencia, tales como (i) el nombre del posible comprador $y$, en caso de ser persona jurídica, el de sus principales socios o accionistas, (ii) el número y clase de las acciones que se desea transferir, (iii) el precio y (iv) demás condiciones de la transferencia.

Cabe mencionar que, en caso de tratarse de una transferencia de acciones distinta a la compraventa, ya sea a título oneroso o a título gratuito, la valorización del precio de las acciones será el contemplado en el estatuto o el que acuerden las partes. A falta de pacto o de acuerdo, el precio lo determinará el juez por proceso sumarísimo.

Como segundo paso, el gerente general, dentro de los diez días siguientes de recibida la comunicación, la pondrá en conocimiento de los demás accionistas para que, en un plazo de treinta días, ejerzan su DAP de manera proporcional a su participación en el accionariado de la SAC.

Como último paso, si después de haber transcurrido sesenta días de haberse realizado la comunicación a la sociedad, los demás accionistas y/o la sociedad ${ }^{33}$ no hubieran comunicado su

33. Nótese que en este artículo se menciona no solo a los accionistas sino también a la misma sociedad. Es decir, además de los accionistas, la SAC es también titular del DAP. Tal derecho está establecido en el tercer párrafo del 
intención de adquirir las acciones, el accionista podrá realizar la transferencia de sus acciones en las mismas condiciones comunicadas.

Al respecto, es oportuno mencionar que, como se deriva del artículo en comentario, el plazo máximo dentro del cual se debe ejercer el DAP es sesenta días contados desde que se realizó la comunicación a la sociedad, ello independientemente de los plazos con los que cuenten tanto el gerente general como los demás accionistas o la sociedad dentro de este proceso.

Finalmente, la consecuencia de la inobservancia del DAP en una transferencia de acciones por parte del accionista, ya sea por no seguir el procedimiento establecido o por transferir sus acciones en forma distinta a la comunicada, es la ineficacia frente a la sociedad de la transferencia realizada ${ }^{34}$.

En líneas generales, es este el procedimiento a seguir en el marco de una transferencia de acciones de una SAC. En la práctica, este mismo procedimiento suele ser plasmado por las SAC en el estatuto con ciertas modificaciones, incluyéndose por ejemplo una segunda ronda de ejercicio del DAP; asimismo, similar procedimiento es regulado por las sociedades anónimas regulares cuando deciden adoptar un DAP.

Ahora bien, antes de realizar un análisis de las situaciones problemáticas que se pueden derivar de la adopción de este procedimiento de ejercicio del DAP en una sociedad anónima, es necesario realizar previamente un análisis de la naturaleza jurídica de cada elemento contenido en este procedimiento, así como de los efectos jurídicos que generan. Ello, con la finalidad de tener un panorama más claro de cómo opera el ejercicio del DAP en una sociedad y, a la larga, evitar o reducir situaciones problemáticas.

\section{PERSPECTIVA CIVIL DEL DAP}

Hasta este punto el análisis del DAP ha sido desarrollado principalmente en términos societarios. Sin embargo, para una cabal comprensión de qué significa ejercer un DAP, creemos necesario analizarlo también desde la óptica civil.

El DAP se enmarca dentro una potencial transferencia de acciones por parte de un accionista, siendo una prerrogativa otorgada a los accionistas de una sociedad para que sean preferidos en la adquisición de tales acciones. En términos civiles, se podría decir que el DAP es aquel derecho que tienen los accionistas de una sociedad a recibir, en caso de presentarse una oferta de adquisición de las acciones de otro accionista, la preferencia en la compra de tales acciones.

Visto así, el proceso de ejercicio del DAP no es otra cosa que un proceso que podrá culminar con la formación de un contrato de compraventa de acciones entre el accionista que pretende transferir sus acciones y los titulares del DAP. En ese sentido, dado que la normativa societaria no regula el proceso de formación de un contrato de compraventa de acciones, es necesario recurrir además a la normativa civil.

Ahora bien, como ya mencionamos, en la práctica comercial la regulación y ejercicio del DAP contenidas en los estatutos de las sociedades anónimas, tanto regulares como en las SAC, es la contenida en el artículo 237 de la LGS, ello principalmente porque los accionistas de estas sociedades la suelen incorporar sin mayores cambios, o en el caso de las SAC, simplemente no es regulada, por lo cual es aplicada de manera supletoria.

Tomando ello en cuenta, el análisis civil se realizará respecto de tal procedimiento en específico

artículo 238 de la LGS que señala que "En cualquier caso de transferencia de acciones y cuando los accionistas no ejerciten su derecho de adquisición preferente, la sociedad podrá adquirir las acciones por acuerdo adoptado por una mayoría, no inferior a la mitad del capital suscrito".

34. "Artículo 241.- Ineficacia de la transferencia

Es ineficaz frente a la sociedad la transferencia de acciones que no se sujete a lo establecido en este título." 
y de los elementos que lo conforman, pudiendo ser este análisis generalizado a cualquier otro procedimiento de DAP. En adelante, retomaremos las definiciones de los actores involucrados en el proceso de ejercicio del DAP: el Accionista Vendedor, los Accionistas Titulares y el Tercero Interesado, y analizaremos la calificación jurídica de los actos en los cuales cada uno participa y los efectos jurídicos que generan.

\section{La comunicación que realiza el Accionista Vendedor es una oferta.}

Lo primero que debemos poner de manifiesto es que, el eventual contrato de compraventa de acciones que se perfeccione como resultado del ejercicio del DAP por parte de los Accionistas Titulares $^{35}$ será un típico contrato conformado por una oferta y por la aceptación de esa oferta.

En ese marco, de acuerdo con el artículo 237 de la LGS, en caso el Accionista Vendedor desee transferir total o parcialmente sus acciones a un Tercero Interesado ${ }^{36}$, debe enviar primero una comunicación a la sociedad. Esta comunicación, jurídicamente y en términos civiles, es una oferta de venta de las acciones del Accionista Vendedor dirigida a los Accionistas Titulares.

Así, si entendemos a la oferta como aquella:

$$
\text { “(...) declaración que una o más partes hace }
$$
a otra u otras, sometiendo a su consideración la celebración de un determinado contrato, en tal forma que para que éste se celebre sólo se requiere la aceptación del destinatario, sin necesidad de que se produzca una nueva declaración del oferente ${ }^{1 / 37}$.

Tenemos que la comunicación que envía el Accionista Vendedor es una auténtica oferta contractual dirigida a los Accionistas Titulares para que estos puedan comprar la totalidad de las acciones ofrecidas.

Su calificación como oferta se deriva del propio artículo que exige que esta comunicación emitida por el Accionista Vendedor - oferente - sea dirigida a los Accionistas Vendedores - receptores de la oferta-, así como que contenga los siguientes elementos -básicos de una compraventa-: (i) el bien objeto de transferencia, que serán el número y la clase de acciones a transferir, y (ii) el precio a pagar por las acciones. A los cuales se les adicionará (iii) las demás condiciones de la transferencia ${ }^{38}$.

Por lo tanto, esta comunicación si es realizada ajustándose a los términos requeridos por el artículo 237 de la LGS, será una auténtica oferta ya que cumplirá con los requisitos aceptados por la doctrina para su existencia ${ }^{39}$, en cuanto será (i) completa o autosuficiente, (ii) se emitirá con una intención seria de contratar y (iii) revestirá la forma requerida.

35. En este caso específico de análisis dentro de la definición de Accionistas Titulares podemos considerar también a la SAC, dado que los artículos 237 y 238 de la LGS la incluyen como titular del DAP.

36. En este caso específico de análisis el Tercero Interesado puede ser también otro accionista, según lo regulado en el artículo 237 de la LGS.

37. FORNO FLOREZ, Hugo. "La oferta al público: Razones para una discrepancia". En: Derecho PUCP N 45. Lima: 1991, p. 216.

38. Cabe mencionar que los términos de la oferta que será comunicada a los Accionistas Titulares podrán venir determinados inicialmente por el Tercero Interesado, en caso haber sido éste quien comunicó en primer lugar su intención de adquisición al Accionista Vendedor; o, también, pueden ser determinados por el mismo Accionista Vendedor en caso sea él quien vaya a realizar la propuesta de venta al Tercero Interesado. En ambos casos, consideramos que el Accionista Vendedor podrá adicionar los términos y condiciones que considere convenientes en la comunicación —oferta - a ser enviada a los Accionistas Titulares; claro, siempre con la salvedad de que, en caso éstos no acepten su oferta, tendrá que realizar la venta de las acciones al Tercero Interesado en los mismos términos y condiciones comunicados.

39. FORNO FLOREZ, Hugo. Op. Cit. 216. 
La comunicación para el ejercicio del DAP, que contiene la oferta, será completa en cuanto, como mencionamos, contemple todos los elementos esenciales del futuro contrato de compraventa, así como las demás condiciones de la transferencia. Eso la hará autosuficiente para que, una vez aceptada por los Accionistas Titulares, se perfeccione automáticamente el contrato de compraventa de acciones.

Además, esta comunicación se emitirá con la seria intención de contratar por parte del Accionista Vendedor, dado que el mismo será consciente que, de mediar la aceptación conjunta por parte de todos los Accionistas Titulares, quedará obligado a transferirles sus acciones en venta. Asimismo, la comunicación revestirá la forma por escrito requerida por dicho artículo, en cuanto se emitirá en forma de carta dirigida a los Accionistas Titulares a través de la sociedad.

Es importante indicar que, adicionalmente, el artículo 237 de la LGS requiere que la comunicación que envíe el Accionista Vendedor incorpore el nombre del Tercero Interesado y, de ser persona jurídica, el de sus principales socios o accionistas. Este requerimiento, más que ser un elemento de esta oferta, se enmarca como requisito para un adecuado ejercicio del DAP por parte de los Accionistas Titulares, ya que, sobre la base de esa información, decidirán si aceptan o no la oferta y con ello su aceptación o rechazo a la entrada del Tercero Interesado a la sociedad.

Así las cosas, teniendo una comunicación del Accionista Vendedor que se constituye como una autentica oferta, luego para la celebración del futuro contrato de compraventa de las acciones será necesario únicamente la aceptación de esa oferta por parte de los Accionistas Titulares.

Confirmada la naturaleza jurídica de esta comunicación como una oferta contractual para la celebración de un contrato de compraventa de acciones, es oportuno pronunciarnos acerca del plazo de vigencia que la misma tendría en el marco del artículo 237 de la LGS.

Es común que una oferta tenga un plazo de vigencia dentro del cual pueda ser aceptada por parte de sus destinatarios y al término del cual la oferta quedará sin efectos; en este caso, la oferta contenida en la comunicación del Accionista Vendedor no es la excepción.

En cuanto a la vigencia de la oferta puesta en conocimiento de los Accionistas Titulares para el ejercicio de su DAP, el artículo 237 de la LGS se puede prestar a confusión dado que regula dos plazos que podrían considerarse como el plazo de vigencia de esta oferta.

El primer plazo es el de treinta días que tienen los Accionistas Titulares, luego de recibida la comunicación, para ejercer su DAP.Y el segundo plazo viene dado por la indicación de que, si transcurridos sesenta días de haberse comunicado la oferta a la sociedad, los accionistas y/o la sociedad no hubieran comunicado su voluntad de compra, el Accionista Vendedor quedará habilitado para realizar la transferencia de sus acciones. Vale la pena hacer la precisión que este plazo de sesenta días cuenta desde que los Accionistas Vendedores envían a la gerencia la carta con la propuesta de venta de las acciones, siendo que, si dentro de esos sesenta días la gerencia no pusiera en conocimiento de los Accionistas Titulares la intención de venta de los Accionistas Vendedores, el plazo concluirá - bajo responsabilidad de la gerencia-y los Accionistas Vendedores podrán proceder a vender las acciones al tercero Interesado. En este acápite nos hemos limitado a comentar el plazo de la oferta, no la conveniencia de esta regulación, asunto que será tocado más adelante y que merece especial atención por los graves efectos que su inobservancia puede generar.

Consideramos que, en principio, en una SAC el plazo de vigencia de la oferta contenida en la carta del Accionista Vendedor es de sesenta días contados desde que se efectuó la comunicación a la sociedad, toda vez que es a partir del término de dicho plazo que esta oferta quedará sin efectos y el Accionista Vendedor será libre de transferir sus acciones al Tercero Interesado. Decimos, en principio, porque bien el Accionista Vendedor podría establecer en su oferta un periodo mayor al establecido, sin que

\section{.}


ello signifique una afectación al procedimiento de ejercicio del DAP.

\section{El ejercicio del DAP por parte de los Ac- cionistas Titulares se configura como la aceptación de la oferta.}

A nuestro parecer, la titularidad del DAP por parte de los Accionistas Titulares implica que estos accionistas tienen el poder de decidir, de manera preferente, si aceptan o no la oferta de compra de las acciones realizada por el Accionista Vendedor. Entonces, el proceso de ejercicio del DAP puede concluir con la adquisición o no adquisición de las acciones en venta por parte de los Accionistas Titulares.

En tal sentido, consideramos que el efectivo ejercicio del DAP - o "la comunicación de la voluntad de compra" como indica la LGS- por parte de los Accionistas Titulares se configura como la aceptación de la oferta del Accionista Vendedor. Entonces, un no ejercicio del DAP se dará cuando los Accionistas Titulares no lleguen a adquirir las acciones en venta, ya sea mediante el rechazo expreso de la oferta o por haber transcurrir el plazo de vigencia de la oferta.

En ambos supuestos se habrá realizado un proceso adecuado de ejercicio del DAP por parte de los Accionistas Titulares. Siendo que, por obvias razones, únicamente en caso de que el proceso de ejercicio del DAP culmine con una no compra de las acciones ofertadas, el Accionista
Vendedor quedará habilitado para transferir sus acciones al Tercero Interesado.

Por lo tanto, el efectivo ejercicio del DAP por parte de los Accionistas Titulares se configurará como la aceptación de la oferta realizada por el Accionista Vendedor. En ese sentido, se regirá por las reglas aplicables a la aceptación contractual, por lo cual tendrá que (i) ser oportuna, esto es, ser puesta en conocimiento del Accionista Vendedor dentro del plazo de vigencia de la oferta ${ }^{40}$; (ii) ser incondicionada, esto es, se deberá aceptar la oferta tal cual, sin realizar cambios o adiciones ${ }^{41}$; $y$ (iii) seguir la formalidad establecida en la oferta ${ }^{42}$; de lo contrario, no surtirá efectos como una aceptación contractual.

Es importante mencionar, en este punto, que el sentido del artículo 237 de la LGS y de la regulación de un DAP en general, va referido a que la aceptación de la oferta por parte de los Accionistas Titulares tiene que ser sobre la totalidad de las acciones en venta. Es decir, para que la aceptación cumpla con ser incondicionada, tiene que ir referida a la totalidad de las acciones en venta, lo cual significa que todos los Accionistas Titulares tendrán que ejercer su DAP para que la venta de las acciones se concretice; de lo contrario, ello significará un rechazo de la oferta realizada por el Accionista Vendedor ${ }^{43}$.

Es esa la interpretación que se le debe dar a un ejercicio efectivo del DAP por parte de los Accionistas Titulares. Por lo que, para que se

40. Código Civil: Artículo 1375.-" "La aceptación debe llegar a conocimiento del oferente dentro del plazo establecido por él".

41. Código Civil: Artículo 1376.- "La aceptación tardía y la oportuna que no sea conforme a la oferta equivalen a una contraoferta.

Sin embargo, el oferente puede considerar eficaz la aceptación tardía o la que se haga con modificaciones, con tal que dé inmediato aviso en ese sentido al aceptante."

42. Código Civil: Artículo 1378.- "No tiene efectos la aceptación que se formule sin observarse la forma requerida por el oferente".

43. Una interpretación contraria significaría que el Accionista Vendedor debería verse obligado a vender solo una parte de sus acciones ofrecidas y no la totalidad. Ello significaría, mínimamente un doble perjuicio, uno ya que la oferta - recibida o a realizar - al Tercero Interesado versaba sobre la totalidad de la cantidad de acciones ofertadas, lo cual frustraría la transacción con este tercero; y otro porque verá disminuida su participación y por ende su poder dentro de la sociedad; o incluso en caso su intención haya sido vender la totalidad de su accionariado, la compra parcial lo haría verse obligado a continuar en la sociedad. Claramente, este no es el sentido de regular un DAP. 
lleve a cabo la transferencia de las acciones ofertadas por el Accionista Vendedor, la aceptación de la compra de tales acciones debe provenir de todos los Accionistas Titulares, esto es, todos deben ejercer su DAP y cada uno respecto del monto proporcional que les corresponde - a prorrata de su participación en el capital-. Todo ello, dentro del plazo establecido para tal ejercicio, el mismo que para el caso del artículo 237 es de treinta días desde recibida la comunicación por parte del gerente general.

Respecto a este último punto, es importante mencionar que los Accionistas Titulares, además de velar por convencerse entre sí de ejercer su DAP para evitar la entrada del Tercero Interesado a su sociedad, deberán cuidar que el plazo de treinta días que tienen para aceptar la oferta del Accionista Vendedor esté dentro del plazo de sesenta días, establecido para la vigencia de la oferta. Ya que, podría darse el caso de que la comunicación por parte del gerente general no les sea comunicada con una anticipación de al menos treinta días del vencimiento del plazo de la oferta, teniendo con ello menos tiempo para proceder con su aceptación ${ }^{44}$.

3. Perfeccionamiento del contrato de compraventa de acciones como resultado de la aceptación por parte de los Accionistas Titulares de la oferta del Accionista Vendedor.

De encontrarnos en el caso de que todos los Accionistas Titulares hayan decidido ejercer su DAP, esto es, aceptando la oferta del Accionista Vendedor, el resultado inmediato del proceso de ejercicio del DAP será el perfeccionamiento de un contrato de compraventa de acciones entre ambas partes. Ello, toda vez que, de acuerdo con el artículo 1373 del Código Civil "el contrato queda perfeccionado en el momento y lugar en que la aceptación es conocida por el oferente".
Esto es importante dado que, en este escenario, con la culminación del proceso de ejercicio del DAP, las partes quedarán vinculadas contractualmente y, por tanto, obligadas (i) a realizar la transferencia de las acciones, en el caso del Accionista Vendedor, y (ii) a pagar el precio establecido, en el caso de los Accionistas Titulares; en los términos y condiciones determinados en la oferta que ahora se ha convertido en el contrato de compraventa de acciones. Ello, sin la obligación ni necesidad de tener que realizar mayores negociaciones sobre los elementos esenciales de la compraventa de las acciones. La pregunta que salta de inmediato es, ¿qué sucede si los Accionistas Titulares ejercen su DAP, pero en la carta de aceptación incluyen elementos adicionales a los comunicados por los Accionistas Vendedores? Por ejemplo, los Accionistas Titulares válidamente podrían querer regular en el contrato de compraventa una cláusula de no competencia - un non-compete-, ¿cómo calza ello en el ejercicio regular de este derecho? En este caso, estaríamos ante una contraoferta, y ello abre nuevas posibilidades de análisis. Por tema de espacio y tiempo, no ahondaremos en esta arista, pero dejamos abierta la discusión sobre las consecuencias que se generarían en este escenario.

Como corolario sobre este acápite, tenemos que mencionar que, la calificación de la comunicación que realiza el Accionista Vendedor como una oferta y del ejercicio del DAP por parte de los Accionistas Titulares como una aceptación, nos permite también la aplicación de las reglas de notificación y conocimiento contenidas en el Código Civil para este tipo de estas declaraciones contractuales. Ello es importante dado que, la LGS no contiene reglas específicas sobre notificación en este tipo de casos y podría ser también que el estatuto no prevea expresamente que reglas seguir, en tales escenarios la aplicación de las reglas del Código Civil nos permite tener certeza respecto a los efectos e implicancias de estas declaraciones.

44. En este escenario, de acuerdo con las circunstancias en concreto, el gerente general tendrá que responder por los perjuicios que ello les generé. Sin embargo, hacemos la salvedad que, un análisis detallado de la responsabilidad del gerente general en el proceso de ejercicio del DAP, por temas de tiempo y espacio, no podrá ser desarrollados en este artículo, dejando su estudio y análisis para otra ocasión. 
Entonces, salvo que se haya pactado algo distinto para el ejercicio del DAP, en aplicación del artículo 1374 del Código Civil ${ }^{45}$, la comunicación emitida por el Accionista Vendedor, canalizada a través del gerente general de la sociedad así como la aceptación producto del ejercicio del DAP por parte de los Accionistas Titulares, se considerarán conocidas en el momento en que lleguen a la dirección de sus respectivos destinatarios; salvo que prueben haberse encontrado, sin su culpa, en la imposibilidad de conocerlas.

\section{SITUACIONES PROBLEMÁTICAS EN TORNO AL PROCESO DE EJERCICIO DEL DAP}

Habiendo sido explicados los aspectos esenciales del DAP en sus aspectos societarios, económicos y civiles, es el momento de plantear y analizar las situaciones problemáticas que se pueden presentar en la práctica ante la presencia de un DAP en una sociedad anónima. A efectos de este análisis, nuevamente, tomaremos como base la regulación del artículo 237 de la LGS que, como indicamos, suele ser el prospecto de regulación del DAP en las sociedades anónimas.

En ese contexto, lo primero que debemos preguntarnos al analizar el artículo 237 de la LGS en el plano práctico es si la regulación que contiene otorga reglas claras y suficientes a los actores que intervienen en el proceso. A nuestro parecer, su aplicación directa, sin ninguna regulación adicional o complementaria, podría ser insuficiente para enfrentar y resolver diver- sos problemas que pueden presentarse en el marco de una transacción - que es el escenario donde debe demostrar su valía para satisfacer los intereses de los involucrados-siendo que, a la postre podría convertirse en un auténtico deal-breaker de una transacción, tal como pasaremos a explicar.

\section{1. ¿Qué significa ejercer el DAP?}

Una de las principales cuestiones problemáticas que se presentan cuando estamos frente a un DAP es la de determinar qué significa precisamente ejercer el DAP y cuáles son las consecuencias de tal ejercicio. Lo transcendental de esta cuestión es el establecer desde qué momento, a propósito de tal ejercicio, la transferencia de las acciones en venta se tendría que realizar.

En otras palabras, ante el ofrecimiento de las acciones por parte del Accionista Vendedor a los Accionistas Titulares para que estos ejerzan su DAP, y suponiendo que éstos en efecto proceden con el ejercicio en conjunto del mismo, surge la pregunta de ¿qué efectos tiene este ejercicio?, y de ¿cómo ello influye en la determinación del momento en el que (i) se tendría que transferir las acciones y (ii) pagar el precio por las mismas?

De lo ya explicado, tenemos que el ejercicio del DAP implica la aceptación por parte de todos los Accionistas Titulares de la oferta realizada por el Accionista Vendedor, aceptación que se va a ver concretizada con la emisión de una comunicación, en ese sentido, por parte de estos, hacía el Accionista Vendedor ${ }^{46}$. Como consecuencia

\section{5. "Artículo 1374.- Conocimiento y contratación entre ausentes}

La oferta, su revocación, la aceptación y cualquier otra declaración contractual dirigida a determinada persona se consideran conocidas en el momento en que llegan a la dirección del destinatario, a no ser que este pruebe haberse encontrado, sin su culpa, en la imposibilidad de conocerla.

Si se realiza a través de medios electrónicos, ópticos u otro análogo, se presumirá la recepción de la declaración contractual, cuando el remitente reciba el acuse de recibo."

46. Una cuestión adicional en este punto es determinar quién debe ser el receptor de la comunicación de los Accionistas Titulares, es decir, si el destinatario sería el gerente general, que fue quien canalizó la oferta del Accionista Vendedor, o si tendría que ser el mismo Accionista Vendedor. Nos inclinamos por considerar que el receptor de la comunicación es el Accionista Vendedor, en cuanto emisor de la oferta, por lo cual el ejercicio del DAP se considerará válidamente realizado de esa manera. No obstante, a fines de evitar posibles contingencias, recomendamos que la comunicación se realice con copia a la sociedad, a través de su gerente general. 
de tal ejercicio, se perfeccionará el contrato de compraventa de acciones entre el Accionista Vendedor y los Accionistas Titulares.

En ese contexto, el ejercicio del DAP tendrá como resultado la celebración de un contrato de compraventa de acciones, del mismo que, salvo estipulación diferente establecida en la oferta, surgirán automáticamente las obligaciones de (i) transferir las acciones por parte del Accionista Vendedor y (ii) de pagar el precio por parte de los Accionistas Titulares, convertidos ya en accionistas compradores.

Ello es importante toda vez que, dado que estamos ante un contrato válidamente celebrado, no será necesario la negociación y/o celebración de acuerdos adicionales de cara al cumplimiento de las obligaciones de ese contrato, salvo que se haya estipulado algo distinto en la oferta. Así, en la práctica surge la pregunta de, ¿en qué momento se tendrían que cumplir estas obligaciones?

Tal pregunta será una cuestión que puede presentar serias dificultades en la práctica, dado que luego del ejercicio del DAP, tanto al Accionista Vendedor como a los Accionistas Titulares, les interesará saber en qué momento se tendrá que realizar el pago por las acciones. Al Accionista Vendedor le interesará recibir el pago por sus acciones lo más pronto posible, mientras que los Accionistas Titulares desearán tener un plazo más prolongado para realizar el pago.

Sin embargo, más allá de los intereses de ambas partes, se tendrá que verificar las reglas establecidas para tal escenario. En primer lugar, la respuesta puede ser encontrada en el texto mismo de la oferta, claro, en caso ello haya sido objeto de regulación. De no haber sido así, se tendrá que verificar qué dice el estatuto; de no encontrar allí la solución, se tendrá que analizar la normativa societaria aplicable, la cual no contiene una regla específica para ese caso; por lo cual será necesario analizar la normativa legal supletoria aplicable al cumplimiento de las obligaciones.

Al respecto, las reglas supletorias aplicables al cumplimiento de las obligaciones las encon- tramos en el Código Civil, específicamente en el artículo 1240 referido al plazo para realizar el pago - llámese cumplimiento- de una obligación. El mismo establece que "si no hubiese plazo designado, el acreedor puede exigir el pago inmediatamente después de contraída la obligación". Con lo cual, en este escenario, el Accionista Vendedor podría solicitar que se le pague el precio por sus acciones inmediatamente después de recibida la comunicación del ejercicio del DAP por parte de los Accionistas Titulares, momento en el cual, como indicamos, queda perfeccionado el contrato de compraventa de acciones y surgen las obligaciones del mismo.

No obstante, esta solución en el marco de una transacción de $M \& A$, por ejemplo, podría traer más problemas que soluciones dado que, tomando en cuenta la transcendencia de cada transacción, los montos involucrados podrían ser de considerable cuantía y no siempre los Accionistas Titulares van a tener a su disposición los fondos necesarios para efectuar dicho pago.

Por lo dicho, lo recomendable sería regular, de manera razonable, el plazo que se tendría para cumplir tanto con la obligación de pago, como con la transferencia de las acciones. Tal regulación podría ser establecida ya sea (i) en el estatuto de la sociedad, (ii) en el convenio que contiene el DAP, según corresponda, o (ii) en la oferta misma.

El optar por una u otra opción dependerá del análisis previo que realicen los accionistas al establecer un DAP en el estatuto o un convenio de accionistas. Recuérdese que, en ese momento, cualquiera de los accionistas podrá en el futuro tener el rol de Accionista Vendedor o de Accionistas Titulares, por lo cual lo que establezcan les será aplicables a todos los accionistas involucrados sin ninguna diferenciación.

Si se opta por establecer un plazo fijo en el estatuto o en el convenio para el cumplimiento de las obligaciones, una vez ejercido el DAP, se tendrá que tener en consideración que el mismo sea lo suficientemente largo como para que los Accionistas Titulares tengan el tiempo necesario de conseguir el financiamiento para el

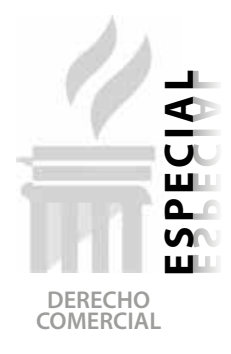

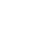


pago de las acciones, pero no tan extenso como para dejar al Accionista Vendedor por un buen tiempo sin el pago de sus acciones. Esta opción se podría decir que resguarda de mejor manera a los Accionistas Titulares dado que tendrán una mejor certeza del plazo para realizar el pago de las acciones ante el eventual ejercicio de su DAP.

La otra opción sería regular que el plazo será el establecido en cada comunicación -llámese oferta- que realice el eventual Accionista Vendedor, toda vez que cada transacción puede tener características distintas que ameriten otorgar plazos más o menos largos, según corresponda, a los Accionistas Titulares. En ese sentido, esta opción sería más flexible de cara a cada transacción en específico. Además, y en principio, sería más favorable para el Accionista Vendedor y para el Tercero Interesado, dado que al poder plantear el Accionista Vendedor el plazo para la realización del pago, este será más o menos largo de acuerdo con la propuesta del Tercero Interesado.

Sea cual fuere la opción, de acuerdo con los intereses que se deseen proteger y satisfacer, sería recomendable que se establezca que, ante el no pago del precio dentro del plazo establecido, el Accionista Vendedor quedará liberado para transferir sus acciones al Tercero Interesado, sin necesidad de activar nuevamente el DAP. De esa manera, se instaura un incentivo -o desincentivo, según como se lo mire- para que los Accionistas Titulares que ejercieron su DAP cumplan con el pago del precio dentro del plazo establecido y no dilaten innecesariamente el cierre de la transacción. Así, se protege al Accionista Vendedor ante una posible frustración de la transacción con el Tercero Interesado debido al ejercido el DAP; y a su vez, el Tercero Interesado tendrá una oportunidad adicional de poder adquirir las acciones en venta, a pesar de haber mediado un ejercicio del DAP.

No obstante tener a disposición estas opciones, debemos recordar que a priori los accionistas que decidan regular un DAP no sabrán que accionista ocupará el rol de Accionista Vendedor o el de Accionistas Titulares en el futuro, por ello se tendrá que arribar a una solución intermedia y razonable que no perjudique o beneficie de sobre manera a los accionistas involucrados cuando, más adelante, tengan que estar en una u otra posición en el marco del ejercicio del DAP.

\section{2. ¿Cuál debe ser el plazo para ejercer el DAP?}

Lo mencionado sobre los plazos para el cumplimiento de las obligaciones de pago del precio y de la transferencia de las acciones, puede ser trasladada a la cuestión de determinar qué plazo establecer para el ejercicio del DAP, como veremos a continuación. Lo cual se puede presentar también como una situación problemática al momento de ejercer el DAP.

Antes, es oportuno mencionar que, ya sea que estemos ante una SAC en la cual, como vimos, el DAP se aplica supletoriamente salvo que se haya establecido algo distinto en el estatuto de la SAC; o ante sociedades anónimas ordinarias que regularon el DAP en su pacto social, en su estatuto o un convenio de accionistas; sea cual fuere el caso, lo recomendable será no adaptar, sin mayor cambio, la regulación del artículo 237 de la LGS.

La regulación del DAP en nuestra LGS es una regulación sencilla, que no está prevista para solucionar situaciones complejas y cambiantes de transferencias de acciones - como lo son las transacciones de M\&A-, las mismas que actualmente tienen un ritmo distinto al que tenían al momento de la dación de esta ley. Por lo cual, en caso los accionistas quieran tener a su disposición un DAP, lo recomendable es que realicen una regulación más amplia y detallada del DAP y de su proceso de ejercicio, teniendo en cuenta la especial situación de su sociedad. Ello con la finalidad de prever futuras potenciales situaciones problemáticas que pueden, a la larga, tener graves consecuencias como el frustrar una transacción por falta de reglas claras y eficaces.

Ahora bien, volviendo al tema del plazo para el ejercicio del DAP, la LGS establece un plazo de treinta días para que los Accionistas Titulares procedan a ejercer su DAP. Sin embargo, este plazo, según el contexto especifico de la tran- 
sacción, podría ser muy largo o muy corto ${ }^{47}$. Por lo que, nuevamente, los accionistas tendrán que decidir si regulan un plazo fijo en el estatuto o convenio, según corresponda; o si, por el contrario, el plazo sea uno variable a ser determinado en cada oferta en específico que se realice.

Los intereses en cuestión son los mismos mencionados para el caso de la obligación del pago del precio detallados líneas atrás. A lo cual adicionalmente debe agregarse que la duración del plazo para el ejercicio del DAP impactará no solo a las partes involucradas, sino también al Tercero Interesado. En líneas generales y en principio, un plazo corto incentivará a que continúe interesado en la transacción, contrariamente, un plazo muy largo, propiciará su pérdida de interés en la adquisición de tales acciones.

Más allá de la opción que tomen los accionistas para regular los plazos del DAP, es necesario tener en cuenta que el proceso de ejercicio del DAP, tanto para el ejercicio mismo, como para el cumplimiento de las obligaciones que de él se deriven, se deben enmarcar en plazos razonables y deberán respetar la buena fe comercial.

Adicionalmente, debe regularse un adecuado proceso de notificación por parte del gerente general de la sociedad a los Accionistas Titulares, ya que como indica Mila Guillén:

“(...) la demora del trámite de comunicación de la sociedad a los socios puede originar graves perjuicios a ambos", adicionando que "en esta clase de transacciones, es muy común que la aceptación y el pago se realice en forma simultánea y ello implica no solo la manifestación de la voluntad, sino la disponibilidad de los fondos para la realización del pago, lo cual no depende exclusivamente del comprador, sies que se trata de conseguir un financiamiento de tercero" ${ }^{\prime \prime 8}$.
Coincidimos con que la demora en la notificación de los Accionistas Titulares puede originar perjuicios por la necesidad de conseguir el financiamiento, y para el análisis de la oferta para la eventual adquisición; sin embargo, creemos que no es exacto afirmar que en este tipo de transacciones sea común que la aceptación y el pago se realicen en el mismo momento, situación que se podría convertir en uno de los problemas en el marco del DAP. Efectivamente, mientras que los vendedores quieren asegurar que el ejercicio del DAP venga aparejado con el pago del precio por la venta de las acciones - de lo contrario podrían perder la oportunidad de vender las acciones al tercero y quedarse con una obligación insatisfecha-, el Accionista Titular pedirá un tiempo razonable para poder evaluar el ejercicio del DAP, y de ejercerlo, un tiempo razonable conseguir los recursos para pagar el precio. Un único plazo de treinta días para cumplir con ambos supuestos podría resultar siendo corto.

Ahora bien, el establecer plazos no razonables - ya sea demasiado largos o cortos- podría terminar teniendo como consecuencia la impracticabilidad del ejercicio del DAP con los consecuentes problemas que ello ocasionaría. En ese escenario todas las ventajas que el DAP puede traer consigo se anulan y se convierten en desventajas para los accionistas involucrados ya que más que una oportunidad de satisfacción de intereses se volverá en una causa de pérdida de oportunidades.

\section{3. ¿Cómo entender la previsión de que los Accionistas Titulares ejercerán su DAP “a prorrata" de su participación en el capital de la sociedad?}

El artículo 237 establece que los Accionistas Titulares ejercerán su DAP a prorrata de su

47. En efecto, desde que los Accionistas Titulares reciben la comunicación para el ejercicio de su DAP, deben pasar por un proceso cuidadoso de análisis donde evaluarán, entre otras cosas, las condiciones de la oferta —y no solo el precio-; si están en capacidad de conseguir los fondos necesarios; si les convendría, de ser el caso, quedarse como accionistas minoritarios con el Tercero Interesado; si existe la posibilidad de sumarse a la venta de tales acciones; si es necesario realizar una contra oferta, entre otras variables. Lo cual, como se ve, tomará un tiempo considerable de acuerdo con la transacción del caso en concreto.

48. GUILLÉN RISPA, Mila. Op. Cit., p. 914. 
participación en el capital de la sociedad. Ya adelantamos que para que se dé un efectivo ejercicio del DAP que conlleve a la transferencia de las acciones del Accionista Vendedor hacía los Accionistas Titulares, estos últimos tendrán que ejercer su DAP sobre todas las acciones en venta $\mathrm{O}$, en otras palabras, tendrán todo que aceptar la oferta por la totalidad de las acciones en venta.

En ese contexto, el ejercicio a prorrata de la participación de los Accionistas Titulares en la sociedad significará primero, que tendrán que aceptar la oferta con los otros titulares y específicamente cada accionista lo hará de la parte proporcional que les corresponda; y segundo, que una vez ejercido el DAP, cada accionista recibirá del total de acciones compradas, una proporción especifica de acciones correspondiente a su participación en el capital social.

Así las cosas, nótese que en los términos del artículo 237 de la LGS para que se presente un efectivo ejercicio del DAP que culmine con la adquisición de las acciones y con ello se evite que el Tercero Interesado ingrese a la sociedad, será necesaria la concurrencia del ejercicio del DAP por todos los Accionistas Titulares, de lo contrario la oferta se considerará rechazada. Esta es una situación no querida para aquellos Accionistas Titulares que, teniendo la intención adquirir las acciones en venta, al final no lo van a poder hacer porque otro de los accionistas no quiso ejercer su DAP.

Esta situación problemática se solucionaría incluyendo una ronda adicional de ejercicio del DAP, en la cual sólo los Accionistas Titulares que manifestaron su intención de adquirir las acciones en venta participarían para adquirir, nuevamente de manera proporcional, las accionistas que los otros accionistas no quisieron tomar. De esa manera, este mecanismo les otorga una salida a los Accionistas Titulares que quieran, y estén en la capacidad de, adquirir todas las acciones ofrecidas y así evitar el ingreso del Tercero Interesado a la sociedad.

En este escenario podrían regularse cuantas rondas adicionales se consideren convenientes has- ta que los Accionistas Titulares interesados en la adquisición de las acciones en venta, lleguen a adquirir todas ellas. Además, será necesario que se regule que la procedencia de tales rondas estará condicionada a la adquisición de la totalidad de las acciones en venta y no a menos que esa cantidad. Repetimos, una adquisición parcial mediante el ejercicio de un DAP de las acciones ofrecidas significaría un perjuicio para el Accionista Vendedor, que escapa a la finalidad del establecimiento de un DAP en una sociedad.

Un ejemplo práctico nos ayudará a entender mejor esta situación problemática: Imaginemos una sociedad que cuenta con 120 acciones repartidas entre cuatro accionistas: accionista $A$ -60 acciones-, accionista $B-30$ accionesy accionista $C-15$ acciones-, accionista $D$ -10 acciones $-\mathrm{y}$ accionista $\mathrm{E}-5$ acciones. El accionista A desea transferir la totalidad de sus acciones a un Tercero Interesado, sin embargo, antes tiene que ofrecerlas a los demás accionistas para que ejerzan su DAP regulado en el estatuto de la sociedad.

Ante el envío de la comunicación por parte del Accionista Vendedor, en este caso A, hacía los Accionistas Titulares del DAP, esto es, a los accionistas B, C, D y E; estos podrán ejercer su DAP de manera proporcional a la cantidad de acciones que poseen en la sociedad, o lo que es lo mismo, a prorrata de su participación en el capital. De manera tal que $B$ podrá ejercer su DAP por 30 acciones, $C$ por 15 acciones, $D$ por 10 acciones y $E$ por 5 acciones.

El escenario ideal sería que todos los accionistas decidiesen ejercer su DAP, en tal caso estaremos ante un ejercicio efectivo por parte de los Accionistas Titulares de su DAP.

Distinto es el escenario en el cual uno de los Accionistas Titulares decida no ejercer su DAP, si no se han regulado rondas adicionales, ese no ejercicio implicaría el rechazo de la oferta, toda vez que una aceptación incondicionada de la oferta significa aceptar la oferta completa, en su totalidad y no por partes. Quedando así libre el Accionista Vendedor de transferir sus acciones al Tercero Interesado. 
No obstante, en caso sí se hayan regulado rondas adicionales, ante la negativa de uno de los Accionistas Titulares de ejercer su DAP, los demás podrán en la siguiente ronda seguir adquiriendo de manera proporcional las acciones que ese accionista dejó.

Por ejemplo, si en nuestro caso, en la primera ronda sólo D - por 10 acciones-y E - por 5 acciones- optan por mostrar su intención de compra y no los accionistas $\mathrm{B}$ y $\mathrm{C}$ - que dejan de adquirir 45 acciones - , entonces para la segunda ronda únicamente $D$ y $E$ podrán participar en la adquisición de las acciones que $B$ y $C$ dejaron -D por 30 acciones y E, por 15 acciones. En esta ronda sólo $D$ manifiesta su intención de compra - por las 30 acciones-, quedando así pendientes las acciones que $\mathrm{E}$ decidió no tomar -15 acciones-, por lo cual será necesario realizar una tercera y última ronda para que se decida si $\mathrm{E}$ tiene la intención de adquirir esas acciones faltantes. Si E manifiesta su intención de adquirirlas, entonces se completa el ejercicio del DAP por la totalidad de las acciones ofrecidas. Al final, el ejercicio del DAP se dio únicamente por el accionista $\mathrm{D}$ por 55 acciones y por el accionista E por 5 acciones.

Como se puede notar, la inclusión de rondas adicionales para el ejercicio del DAP de adquisición preferente se presenta como un mecanismo adecuado para que uno o varios Accionistas Titulares puedan tener la opción de adquirir las acciones en venta sin mediar el ejercicio del DAP por la totalidad de ellos. Debe tenerse en cuenta que será importante regular expresamente los plazos que cada ronda adicional tendrá para así evitar complicaciones y dilaciones innecesarias.

\section{4. ¿Qué sucede con la aplicación del DAP ante la presencia de más de un Accionista Vendedor?}

Usualmente, en el marco de las operaciones de $M \& A$ que tengan por objeto la adquisición de acciones de una sociedad, el Tercero Interesado buscará adquirir el control de esa sociedad o, al menos, adquirir una cantidad considerable de acciones que le otorguen poder de decisión en los asuntos sociales. Para ello, puede darse el caso de que la cantidad de acciones de su interés estén en manos no de un único accionista, sino de varios; por lo cual va a tener que negociar con todos esos accionistas.

Asimismo, en determinadas situaciones habrá grupos de accionistas que desearán vender en conjunto sus acciones a un Tercero Interesado con el propósito de hacer líquida su inversión en la sociedad, de manera que no les interesará la adquisición de sus acciones de manera individual sino conjuntamente.

En ambas situaciones, antes de que los accionistas interesados en vender - los Accionistas Vendedores- puedan transferir sus acciones a un Tercero Interesado, tendrán que activar el proceso de ejercicio del DAP. Con ello, en principio, cada uno de los Accionistas Vendedores tendrá que enviar una comunicación a los demás Accionistas Titulares para que decidan si ejercen o no su DAP.

Así, son dos los escenarios no problemáticos que se podrían presentar: (i) que ninguno de los Accionistas Titulares ejerza su DAP, ante lo cual los Accionistas Vendedores podrán transferir sus acciones al Tercero Interesado; y (ii) que todos los Accionistas Titulares ejerzan su DAP respecto de todos los Accionistas Vendedores. Ambos son escenarios no problemáticos dado que se cumple la finalidad de que todos los Accionistas Vendedores transfieran la totalidad de sus acciones en venta.

Sin embargo, puede darse un tercer escenario en el cual los Accionistas Titulares decidan ejercer su DAP solamente respecto de algunos de los Accionistas Vendedores y no de todos, o lo que es lo mismo, que acepten algunas ofertas y no todas. Quedando así únicamente algunos de los Accionistas Vendedores liberados para poder transferir sus acciones.

En este último escenario se presenta la situación problemática de que, recordemos, todos los Accionistas Vendedores pretendían vender sus acciones conjuntamente, ya sea porque así lo deseaban o porque el interés del Tercero Interesado recaía en la adquisición de la totalidad

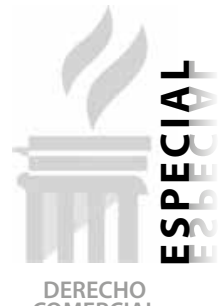

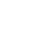


de sus acciones y no solo algunas en algunas de ellas. Con lo cual, los intereses de estos sujetos involucrados no se verán satisfechos, siendo los más perjudicados los Acciones Vendedores que no lograron transferir sus acciones.

Dicho problema se genera, en principio, porque el proceso regulado en el artículo 237 de la LGS está pensado para casos de existencia de un solo Accionista Vendedor, y no necesariamente para el caso de varios Accionistas Vendedores que deseen vender conjuntamente sus acciones. Sin embargo, ¿ello significa que no habría una solución para esta problemática?

Consideramos que, si bien el artículo 237 de la LGS contempla el supuesto de transferencia de las acciones de un solo Accionista Vendedor, nada obsta para que cada uno de los Accionistas Vendedores condicione la venta de sus acciones a la adquisición de las acciones de todos los demás Accionistas Vendedores. La inclusión de esta estipulación será perfectamente válida en la comunicación - oferta- que envíe cada Accionista Vendedor y encajaría como una de las "demás condiciones de la operación", en los términos del artículo 237.

Por lo cual, los Accionistas Titulares no podrían alegar que el ejercicio de su DAP se ve limitado por el establecimiento de tal condición, dado que el Accionista Vendedor se encuentra facultado a incluir las condiciones que considere convenientes a sus intereses en su oferta, con la única limitación que, en caso de no ejercicio del DAP, tendrá que transferir las acciones al Tercero Interesado en las mismas condiciones establecidas en la oferta comunicada a los Accionistas Titulares.

Para que no exista duda de la procedencia de esta estipulación, recomendamos que en la regulación del DAP que sea adoptada, en el estatuto o en el convenio respectivo, se prevea expresamente la posibilidad de activar el proceso de ejercicio del DAP ante la presencia de
Accionistas Vendedores que deseen transferir en conjunto sus acciones. Se evita con ello los cuestionamientos y las situaciones problemáticas que podrían presentarse con el solo acogimiento del proceso del artículo 237 de la LGS.

De esa manera se evita trabar transacciones en las cuales los accionistas de una sociedad pretenden vender en conjunto sus acciones y donde existe un potencial comprador que está interesado en comprarlas únicamente de esa manera. La realidad de las operaciones de adquisición de acciones de hoy en día nos demuestra que este tipo de situaciones son de las más usuales, por lo que el ejercicio del DAP no podría ser entendido como un mecanismo que desincentive y ponga en "jaque" a estas transacciones.

\section{5. ¿Cómo debe ser establecido "el precio" en la comunicación que envíe el Accionista Vendedor?}

Otra de las cuestiones sustanciales y que podría convertirse en una situación problemática al momento de la activación del DAP, viene dada por el establecimiento del precio para la adquisición de las acciones. Como se vio, el artículo 237 de la LGS establece que, entre otras cosas, el Accionista Vendedor deberá incluir en la comunicación - oferta- el precio de las acciones. Ahora bien, la pregunta que surge es si este precio debería estar previamente determinado en su monto exacto o si podría ser un precio determinable.

En la práctica, esta cuestión adquiere mucha relevancia dado que, por ejemplo, en las operaciones de M\&A en su mayoría, el precio de compra de las acciones es determinado sobre la base de una fórmula de cálculo, usualmente el EBITDA ${ }^{49}$. En otras palabras, generalmente, el precio no se encuentra previamente determinado, sino que es determinable. Con lo cual, en la comunicación que el Accionista Vendedor tenga que enviar, colocará no un precio con una cantidad

49. EBITDA es el acrónimo en inglés de Earnings Before Interest, Taxes, Depreciation, and Amortization. 
determinada sino uno susceptible de determinación mediante la fórmula que corresponda.

Ante ello, los Accionistas Titulares podrían objetar que el precio de las acciones incluido en la comunicación no está determinado en un monto exacto y alegar que, por ende, el proceso de ejercicio del DAP no se ha activado. Sin embargo, consideramos que tal objeción sería infundada por dos razones (i) ya que es completamente válido que el precio de compra de acciones sea determinado o determinable - no existe restricción legal en ese sentido-, y (ii) porque de aceptar que el precio solo puede ser determinado, tal requerimiento se convertiría en uno prácticamente imposible de cumplir en la mayoría de los casos, dado que, como mencionamos, la gran mayoría de las transacciones establecen un precio determinable.

Para que no quede duda de ello, es recomendable que se regule expresamente que el requisito de establecer el precio se cumple, ya sea que el mismo esté determinado o sea determinable. Incluso, se puede detallar las formulas y/o metodologías especificas factibles de utilizar. Con ello, al momento de la activación del DAP, el Accionista Vendedor deberá velar porque el precio o su fórmula de determinación sean incorporados de manera clara en la comunicación que envíe a los Accionistas Titulares.

Una cuestión adicional respecto al precio consiste en la determinación del modo de calcular el precio por las acciones. Algunos consideran que la fórmula o el mecanismo de determinación del precio deben estar preestablecidos, ya sea en el estatuto o en el convenio que contiene el DAP. Otros consideran que la determinación del precio debe ser realizada en cada caso en concreto, por lo cual no debería ser fijado previamente, sino venir contemplado en cada comunicación que se envíe ${ }^{50}$.

Nos inclinamos por considerar que el establecer un precio fijo o una única metodología para el cálculo del mismo no sería adecuado, dado el marco en el cual hoy en día se mueven las transacciones. Encasillar el precio podría no ser lo más conveniente para los accionistas, por lo que una determinación variable del precio que responda a las circunstancias, en concreto de la operación, sería más eficiente para los actores involucrados. De cara a que el DAP despliegue sus efectos económicos de la mejor manera, un precio variable se constituye en la mejor opción ${ }^{51}$.

Como indican Di Chiazza y Van Thienen, la eficiencia económica del DAP tiene que ver con el precio y los costes en juego, ya que a partir de ellos se estructura y edifica el sistema de incentivos y desincentivos ${ }^{52}$ que acarrea este derecho de preferencia. Con lo cual, lo más recomendable sería optar por tener un precio variable sin limitaciones en cuanto a su cuantía o modo de cuantificación, que responda y se adapte a las circunstancias concretas de cada transacción.

\section{6. ¿Cómo entender el deber de incluir el nom- bre del posible comprador en la comunica- ción que envíe el Accionista Vendedor?}

El artículo 237 de la LGS establece que, en la comunicación que realice el Accionista Vendedor, deberá constar el nombre del posible comprador y si es persona jurídica, el de sus principales socios o accionistas. Este requerimiento, tal como mencionamos anteriormente, no sería un elemento esencial de la oferta contenida en dicha comunicación, pero sí un requisito funda-

50. "Se sostiene que cualquiera sea el procedimiento para determinar el precio, debe asegurar que éste sea justo para que la preferencia sea lícitamente ejercida, cuando en realidad, la operatividad del RFR es más eficiente en ausencia, ciertamente, de precio alguno o de cláusulas que aten a las partes hacia un determinado precio". DI CHIAZZA, Iván y VAN THIENEN, Pablo. Op. Cit., p. 721.

51. "La inclusión de un precio justo —o de un mecanismo para su determinación objetiva-comprime y encierra al RFR -léase DAP, en nuestro caso-, limitando la posibilidad de su aplicación eficaz y del desarrollo de los efectos propios de cada modalidad". Ibíd., p. 730.

52. Ibíd., p. 721. 
mental para que los Accionistas Titulares tomen una decisión informada sobre si adquirir o no las acciones ofertadas. En otras palabras, este requerimiento es esencial para un adecuado proceso de ejercicio del DAP.

La finalidad de que los Accionistas Titulares conozcan el nombre del posible comprador radica en que puedan realizar un análisis respecto de la conveniencia o no de dejar ingresar a un tercero a su sociedad. Sin este requisito, una de las funciones principales del DAP no se cumpliría. Sin embargo, en la práctica el cumplimiento de este requisito puede presentar algunos problemas que es necesario considerar.

La identificación del Tercero Interesado viene dada por su nombre, ya sea que se trate de persona natural o de persona jurídica, con la salvedad de que, en el caso de personas jurídicas la norma societaria requiere que se consigne además el nombre de sus principales socios o accionistas. Esto último puede generar el primer inconveniente relativo a determinar ¿qué se debe entender por principales socios o accionistas?

No existe una norma societaria que nos indique quiénes serían los principales socios o accionistas en una sociedad. Así, a falta de una disposición legal, el porcentaje de participación nos podría ayudar a resolver esta cuestión. Por lo cual, podría entenderse que los socios o accionistas principales son aquellos que ostentan un porcentaje mayoritario de participación en la persona jurídica. Pero, podría presentarse el inconveniente de que estemos ante sociedades con accionariados difundidos y en los cuales sea difícil la identificación de los accionistas mayoritarios, lo cual también presenta ciertas dificultades.

Así las cosas, respecto a esta primera cuestión, el requisito de establecer el nombre de los principales socios o accionistas en caso de ser el posible comprador una persona jurídica se resolvería, en principio, atendiendo a un criterio de porcentaje mayoritario de participación en la persona jurídica. De acuerdo con el caso en concreto, se tendrá que determinar quiénes son los socios o accionistas que ostentan tal mayoría $y$, ante la duda de la existencia de mayoritarios, se deberá optar por colocar a aquellos que cuenten con mayores participaciones dentro de la persona jurídica.

Complicaciones mayores se presentarían cuando el Tercero Interesado no es propiamente una persona jurídica, tal como podría ser el caso muy común en las operaciones de M\&A actuales que estemos frente a un grupo económico, un fondo de inversión, un family office u otra entidad similar donde no existe un nombre o una razón social definida. Ante tales supuestos, el indicar el nombre o denominación de la entidad respectiva y el proporcionar información suficiente y razonable sobre cómo se encuentra conformada la misma, por criterios de buena fe comercial, podría ser considerado como cumplimiento de este requisito.

Ahora bien, y relacionado con lo dicho en el párrafo anterior, el principal problema con relación al requisito en comentario se podría presentar cuando el Tercero Interesado, que es quien negocia la adquisición de las acciones, no sea necesariamente quien termina adquiriendo directamente las acciones o, en otras palabras, no sea quien termine siendo el futuro accionista de la sociedad. Ello podría suceder en caso el Tercero Interesado sea una de las entidades mencionadas, o porque se esté ante la presencia de una sociedad holding, casos en los cuales la determinación del adquiriente o beneficiario final de las acciones - que bien podría ser una sociedad perteneciente a estos o un vehículo especial creado para tales efectos - se realice a pocos días del cierre de la transacción.

Ante tales situaciones, los Accionistas Titulares podrían objetar que no han sido debidamente informados sobre el potencial verdadero adquiriente de las acciones, y por ende considerar no activado el proceso de ejercicio del DAP. Por lo cual, será importante que el Accionista Vendedor prevea esta potencial fuente de conflictos y establezca detalladamente quién será, en última instancia, el real adquiriente de las acciones.

Nuevamente, para evitar este tipo de complicaciones relacionadas con el deber de consignar 
el nombre del potencial comprador, es recomendable plasmar expresamente en el estatuto o en el convenio respectivo que, ante el tipo de situaciones detalladas, tal deber se cumple con la identificación del ente o de la sociedad holding respectiva, incluyéndose la posibilidad que estos puedan designar al adquiriente final de las acciones que, por obvias razones, tendría que ser necesariamente alguien vinculado a ellos directamente.

Sin perjuicio de ello, se debe tener cuidado de que esta estipulación signifique un mecanismo de elusión para la verdadera finalidad del DAP que se busca satisfacer con este requisito. La cual es, como ya dijimos, que los Accionistas Titulares sean informados adecuada y razonablemente sobre el potencial tercero con quien podrían terminar compartiendo la mesa en el accionariado de su sociedad.

\section{7. ¿Cómo verificar que, en caso de no ejercicio del DAP, el Accionista Vendedor transfiera las acciones en las mismas condiciones informadas a los Accionistas Titulares?}

El artículo 237 es claro al establecer que, transcurrido sesenta días desde que se puso en conocimiento de la sociedad la comunicación por parte de Accionista Vendedor, y sin que los Accionistas Titulares hayan ejercido su DAP, este quedará habilitado a transferir al Tercero Interesado las acciones objeto de venta. También es claro al indicar que tal transferencia tendrá que ser realizada en las mismas condiciones informadas a los Accionistas Titulares.

De realizarse la transferencia de las acciones en condiciones distintas a las contenidas en la comunicación del Accionista Vendedor, en aplicación del artículo 241 de la LGS, tal transferencia sería ineficaz frente a la sociedad por lo cual no le podría ser oponible. Más allá de analizar la situación en la que se encontrarían los actores involucrados del DAP en este escenario $^{53}$-análisis que por cuestiones de tiempo y espacio escapa a este estudio-, tendríamos que preguntarnos ¿cómo la sociedad y/o los Accionistas Titulares podrían verificar que la transferencia de las acciones respetó las condiciones comunicadas?

La LGS no nos proporciona una respuesta a esta pregunta, por lo cual se podría decir que existe un deber implícito de entrega de tal información por parte del Accionista Vendedor y/o, ahora también, del Tercero Interesado a la sociedad o a los Accionistas Titulares, o un derecho de acceso a esta información por parte de éstos últimos, para la verificación de que la transferencia no fue realizada en términos y condiciones más beneficiosas. Sin embargo, dado que no existe un mandato expreso de cómo proceder a realizar tal verificación, ello podría ser otra de las situaciones problemáticas del DAP.

Ya sea aceptando que exista un deber de proporcionar tal información o un derecho de acceder a ella, en la práctica, la comprobación directa se realizaría teniendo a disposición el contrato de compraventa de acciones suscrito, el mismo que podría contener obligaciones de confidencialidad para las partes y la cual podría significar un obstáculo a su acceso. Caso en el cual se podría argumentar que, incluso, una declaración jurada sobre el respecto sería suficiente para indicar que la transacción se realizó en las mismas condiciones comunicadas.

Dada la falta de reglas específicas para realizar tal comprobación, lo más recomendable sería establecer, en el estatuto o en el convenio respectivo, las modalidades y procedimientos específicos de cómo se llevará a cabo tal verificación, con la indicación de los deberes y derechos que les corresponderá a las partes ante tal situación.

53. Cfr.: DE TRAZEGNIES GRANDA, Fernando. Op. Cit., pp. 233 y ss.; ELÍAS LAROSA, Enrique. Op. Cit., pp. 84 y ss.; y GUILLÉN RISPA, Mila. Op. Cit., pp. 913 y ss. 


\section{CONCLUSIONES Y REFLEXIONES FINALES}

Como hemos visto en este artículo, el ejercicio del DAP en un escenario transaccional real puede dar lugar a situaciones problemáticas que, de no ser tratadas de buena fe entre las partes y con reglas claras, podrían generar un quiebre en la transacción. Ello, con la consecuente pérdida de la oportunidad de venta de los Accionistas Vendedores, la pérdida del ingreso de un nuevo accionista a la sociedad que podría generar un valor agregado real y el mantenimiento de un status quo en la sociedad - misma composición accionaria- con la consiguiente pugna y controversia que muy probablemente se geste entre el Accionista Vendedor y los Accionistas Titulares que dada la falta de reglas claras para el ejercicio del DAP frustraron - con o sin intención real- la venta de las acciones por parte de los Accionistas Vendedores.

En este artículo, hemos evidenciado algunas de las principales situaciones problemáticas que se podrían presentar en el marco del ejercicio del DAP, por lo cual nuestro análisis no ha agotado todos los posibles escenarios que podrían causar problemas a los actores del DAP de cada al cierre de una transacción en concreto. Nuestra intención es advertir a los lectores sobre los beneficios que trae consigo el DAP, pero también sobre los potenciales problemas que una inadecuada regulación podría ocasionar.

Si bien es cierto que, para evitar todas las situaciones problemáticas en torno al ejercicio del DAP, tendríamos que ponernos en todos los posibles escenarios y proceder a regularlos en el estatuto o el convenio correspondiente, ello en la práctica sería un irreal e ineficiente. Nuestra propuesta es más factible de realizar, de modo que para los accionistas que deseen contar con un DAP en su sociedad o para aquellos que ya cuenten con el mismo, sugerimos que realicen una regulación detallada y atenta del proceso de ejercicio del DAP, estableciendo reglas claras previendo escenarios problemáticos, como los aquí detallados.

En resumen, entre los principales aspectos que creemos se deben considerar tenemos: a) Delimitación de plazos tanto para el ejercicio del DAP como para el cumplimiento de las obligaciones que de él se deriven.

b) Formalidades adicionales que se deberían cumplir ante el ejercicio del DAP como, por ejemplo, plazos para formalizar el contrato de compraventa de acciones celebrado, entre otras.

c) Definición de los elementos a ser consignados en la comunicación a ser enviada por el Accionista Vendedor.

d) Indicación sobre la posibilidad de establecer un precio determinado o determinable.

e) Posibilidad de existencia de Accionistas Vendedores que deseen transferir sus acciones en bloque.

f) Establecimiento de rondas adicionales de ejercicio del DAP.

g) Procedimientos para la verificación de que la transferencia realizada ante el no ejercicio del DAP se ajusta a las condiciones comunicadas.

h) Regulación detallada sobre la información necesaria para la identificación del posible comprador.

i) Mecanismos rápidos de solución de controversias que se centren específicamente en determinar el cumplimiento del proceso de ejercicio del DAP.

De este modo, concluimos que si los accionistas piensan en una posible operación de venta de sus acciones, una de las primeras cosas que se debería hacer es revisar el estatuto de la sociedad o el convenio respectivo para validar la regulación del DAP establecida y analizar si tal regulación es suficiente para resolver los problemas prácticos que se podrían presentar. De no ser así, como método preventivo de conflictos, la modificación de la regulación del DAP, tomando en consideración los aspectos indicados, sería una de las primeras cuestiones por resolver. 
Por otro lado, desde el lado del Tercero Interesado, es recomendable que, previamente a la emisión de ofertas vinculantes, se proceda a revisar con detenimiento el estatuto de la sociedad y/o los convenios respectivos, para confirmar la existencia de un DAP y analizar la regulación establecida para su ejercicio, y verificar con ello los plazos, acciones y mecanismos que se seguirán. Adicionalmente, podría ser recomendable solicitar la firma de un term sheet, una Carta de Entendimiento o un documento similar donde el Tercero Interesado, luego de formulada la oferta de compra, se cubra ante los potenciales riesgos y daños que le significarían el ejercicio del DAP por parte de los Accionistas
Titulares, trasladando tales riesgos y responsabilidades al Accionista Vendedor.

Finalmente, lo recomendable para todos los actores involucrados en el proceso de ejercicio del DAP es que presten especial atención a los detalles de la regulación del DAP y que analicen ex ante los posibles efectos positivos o negativos que tal regulación les podría generar, para ello el rol de los asesores legales será fundamental para llevar a cabo tal diligencia. Un comportamiento activo de previsión se presenta siempre como la primera opción a considerar y el caso del DAP no es la excepción. 